\title{
La crisis catalana y el desgobierno de los gobiernos de España*
}

\author{
The catalan crisis and the mismanagement \\ of Spanish Governments
}

\author{
Romualdo BERMEJO GARCÍA \\ Catedrático de Derecho Internacional Público \\ Universidad de León (España) \\ rberg@unileon.es
}

\begin{abstract}
Resumen: La denominada crisis catalana ha puesto a España en el tapiz de la actualidad internacional al abrirse una crisis de identidad nunca conocida desde la Guerra Civil española. Cabe preguntarse cómo esto ha podido ocurrir en uno de los Estados más antiguos de Europa, y en un momento crítico para la Unión Europea, aunque, en nuestra opinión, hay que reconocer que en esta crisis una buena parte de la responsabilidad incumbe a los distintos Gobiernos de España, sobre todo a los dos últimos, es decir al Gobierno de José Luís Rodríguez Zapatero, y al de Mariano Rajoy. Si el primero abrió la caja de pandora al apoyar abiertamente la reforma del Estatuto catalán en 2006, en parte después anulada por el Tribunal Constitucional, el segundo ha hecho prueba de una ignominiosa pusilanimidad, permitiendo que el asunto se le fuera de las manos. Así pues, ni uno ni otro han estado a la altura de las circunstancias...
\end{abstract}

Palabras clave: Cataluña; Declaración Unilateral de Independencia; Constitución Española.
Résumé: La crise catalane a mis à l'Espagne dans le tapis de l'actualité internationale, générant ainsi une crise d'identité jamais connue depuis la guerre civile espagnole. On peut se demander, cependant, comment celle-ci a pu avoir lieu dans l'un des pays plus anciens de l'Europe, et dans un moment critique pour l'Union européenne. II faut néanmoins souligner qu'une bonne partie de la responsabilité de cette crise est l'oeuvre des gouvernements espgnols de Madrid, surtout des deux derniers, à savoir celui de José Luís Rodríguez Zapatero, et celui de Mariano Rajoy. Si le premier a ouvert la boîte de pandore en appuiyant ouvertement la réforme de le Statut catalan en 2006, réforme annulée en grande partie par le Tribunal constitutionnel espagnol, le deuxième a fait preuve d'une ignominieuse pusillanimité, en permettant ainsi que la sale affaire devienne incontrolable. Ainsi, ni l'un ni l'autre ont été à l'hauteur de circonstances...

Mots-clés: Catalogne, Déclaration d'indépendance unilatérale, Constitution espagnole.

Sumario: INTRODUCCIÓN. 1. CAUSAS Y ORÍGENES DE LA CRISIS. 2. LOS RETOS DE LA REFORMA DEL ESTATUTO DE AUTONOMÍA DE 2006 Y SUS NEFASTAS CONSECUENCIAS. 3. PERO, ¿PUEDE CATALUÑA RECLAMAR LA INDEPENDENCIA? ALGUNOS BREVES COMENTARIOS A NIVELJURÍDICO INTERNACIONAL. 3.1. Algunos comentarios sobre el derecho de autodeterminación. 3.2. El Tribunal Constitucional español rechaza de plano la autodeterminación catalana. 4. LA CRISIS CATALANA EN LAACTUALIDAD: LOS REFERENDOS Y LAS DECLARACIONES UNILATERALES DE INDEPENDENCIA 4.1. Las reacciones a los referendos. 4.1.1. La Declaración de Independencia del 10 de octubre. 4.1.2. El Senado aprueba la aplicación del artículo 155 de la Constitución. 4.2. La Declaración de Independencia del 27 de octubre de 2017 ¿Real o simbólica? 5. LA CRISIS CATALANA Y LA COOPERACIÓN JUDICIAL EUROPEA: ¿ORDEN O DESORDEN? 6. LAS ELECCIONES DE 21 DE DICIEMBRE CONVOCADAS POR EL GOBIERNO CENTRAL PARA ELEGIR AL PARLAMENTO DE LA COMUNIDAD AUTÓNOMA: ALGUNAS REFLEXIONES. 7. LA MOCIÓN DE CENSURA AL PRESIDENTE DEL GOBIERNO, MARIANO RAJOY, Y LA OFERTA DE DIÁLOGO. CONCLUSIÓN.

* Este estudio se ha publicado en inglés en el fournal of European Studies, $\mathrm{n}^{\circ}$ 7, Universidad Francisco de Vitoria/Instituto de Estudios Europeos, Robert Schuman, diciembre 2018. 


\section{INTRODUCCIÓN}

$L$ a crisis catalana, tal y como se ha venido desarrollando ha desconcertado a propios y a extraños. Muchos no podían dar crédito a lo que estaba sucediendo, hasta que poco a poco fueron comprobando que no era la pesadilla de un sueño, sino una realidad. Es más, la crisis catalana es, sin lugar a dudas, la más grave que ha padecido España no solo en nuestro período democrático, sino desde la guerra civil de 1936-39. El terrorismo de ETA, a pesar de los más de 800 muertos que generó, nunca llegó a representar un peligro para España tan importante como ha supuesto la crisis catalana, problema que sigue estando todavía presente si no se le hace frente con todas las armas de las que dispone un Estado de derecho, como se supone que es España.

Sin embargo, aunque el problema viene de lejos, es evidente que tanto el Gobierno del socialista Rodríguez Zapatero, como el Gobierno de Mariano Rajoy, no han estado a la altura de las circunstancias, y ambos son en nuestra opinión los grandes responsables de cómo ha ido evolucionando la crisis catalana, el primero por incentivarla y, el segundo, porque con su pusilanimidad dejó que fuera hacia el precipicio hasta que el pueblo español reaccionó, decimos bien el pueblo, no el Gobierno. Las últimas informaciones que están saliendo a la luz son realmente demoledoras para un Gobierno que dejaba hacer como si Cataluña ya no formara parte del territorio nacional. Mientras esto ocurría, todos los países europeos y latinoamericanos hicieron declaraciones muy contundentes afirmando que era un asunto interno español, y que la crisis se tenía que resolver según lo previsto en el orden constitucional español. Todos estos mensajes tenían un claro significado, que era que la responsabilidad principal para resolver la crisis correspondía al Estado español, es decir, al Gobierno de España, sin que esto cambiara la pasividad gubernamental. Tanto es así que el sistema judicial español tuvo que tomar cartas en el asunto catalán ante el flegmatismo gubernamental, al haberse cometido delitos graves. Esto explica que la crisis catalana haya llegado donde ha llegado, permitiendo así que se produjera un terrible espectáculo a nivel nacional e internacional.

\section{CAUSAS Y ORÍGENES DE LA CRISIS}

La actual Comunidad Autónoma de Cataluña tiene una historia peculiar, por no decir compleja, pero esto no impide afirmar un dato histórico de primer nivel, y es que este territorio, que nunca fue un Reino, pues formaba 
parte de la Corona de Aragón, forma parte integrante de España desde su creación en 1492. España tiene pues un título histórico y originario sobre este territorio desde entonces a pesar de los grandes avatares de la historia franco-española. Esta realidad histórica trae consigo que cualquier cambio jurídico en este territorio que forma parte integrante de la soberanía española debe ser decidido por el pueblo español, al ser este el único titular de la soberanía nacional, como ha recalcado de una forma cristalina el Tribunal Constitucional español en su Sentencia 42/2014, de 25 de marzo de 2014, en relación con el recurso planteado por el Gobierno de la Nación ${ }^{1}$ respecto de la Resolución del Parlamento de Cataluña 5/X, de 23 de enero de 2013, por la que se aprueba la Declaración de soberanía y del derecho a decidir del pueblo de Cataluña².

Dicho esto, conviene resaltar que no es la primera vez que se proclama una república catalana. Dejando al margen la primera proclamación de Pau Claris en 1641, sin ninguna importancia para este estudio, ya en 1931 se proclamó una república por Francesc Macià, justo una hora antes de la proclamación de la República española en Madrid el 17 de abril de 1931. Sin embargo, tras unas horas de negociaciones, y después de que fracasara el proyecto de una república federal, Macià se ve obligado a aceptar un estatuto de autonomía para Cataluña hasta su muerte en $1933^{3}$. Más problemática sería la proclamación del 6 de octubre de 1934 por parte de Lluís Companys, está en plena República española ${ }^{4}$, que fue abortada en horas al recurrir la República española a la fuerza y bombardeando el Palacio de la Generalitat (gobierno catalán). El destino de Lluís Companys es bien conocido, pues fue ejecutado en 1940 tras haber sido entregado por las fuerzas alemanas que habían ocupado Francia, y tras haber sido condenado por un Consejo de

1 En este trabajo utilizamos indistintamente las expresiones Gobierno de España, Gobierno español, Gobierno de la Nación y Gobierno Central para referirnos al «Gobierno del Estado español». Es cierto que la expresión de Gobierno Central ha ido adquiriendo una cierta divulgación a la luz de los problemas suscitados por ciertas Comunidades Autónomas, reticentes a hablar de Gobierno español o de Gobierno del Estado español.

2 Para el texto de ésta sentencia, muy bien elaborada, cfr: http//www.boe.es/diario_boe/txt. php?id=BOE-A-2014-3885.

3 A este respecto, véase Hernández Lafuente, A., Autonomía e integración en la Segunda República, Encuentro, 1980, 380 p. , especialmente pp. 52 y ss. Igualmente BlinKHORN, M., Carlismo y contrarevolución en España (1931-1939), Critica, 1979, pp. 70 y ss.; y Ualay-Da Cal, E.

4 Sobre esta proclamación, véase CANAL, J., Con permiso de Kafka. El proceso independentista en Cataluña, Península, 2018, pp. 95 y ss.; y DE La Granja, J.L.; Beramendi, J.; ANQUera, P., «La España de los nacionalismos y las autonomías», Síntesis, 2001, pp. 734 y ss. 
Guerra $^{5}$. Pero en la cuestión catalana, otro hecho que no conviene olvidar en el subconsciente independentista actual es que Cataluña ha estado siempre en la turbulenta historia española del lado de los vencidos.

Dos buenos ejemplos ilustran esta afirmación. El primero atañe a la Guerra de Sucesión Española (1701-1714) en la que los catalanes apoyaron a los Habsburgo en contra de los Borbones. Sin embargo, estos últimos ganaron la guerra y toman Barcelona, que es bombardeada sin piedad hasta su caída el 11 de septiembre de 1714, fecha que ha sido la elegida como fiesta nacional catalana, es decir la Diada. El segundo ejemplo es el de la Guerra Civil española de 1936-1939, en la que Cataluña cae de lado republicano y defiende la legalidad de la República frente a la sublevación de ciertos militares, apoyados de forma muy activa por varios sectores políticos y sociales conservadores, entre los que conviene destacar a los tradicionalistas. A pesar de todo, muchos de estos catalanes conservadores lograrían luchar en el bando de los sublevados, al que se incorporan como pueden, muchos de ellos por Francia, logrando formar unidades de élite de combate, cuyo ejemplo más significativo es el famoso Tercio de Requeté, Nuestra Señora de Montserrat ${ }^{6}$.

Si pasamos ahora a la denominada transición española tras el régimen franquista, conviene apuntar que Cataluña votó masivamente por la Constitución actual del 6 de diciembre de 1978 con el 90,5 por cien de votos afirmativos, más que en Madrid, por ejemplo, en donde solo hubo 86,1 por cien. Evidentemente esto quiere decir que los catalanes estaban muy de acuerdo con el régimen de las Comunidades Autónomas que la Constitución adoptó para llevar a cabo la descentralización del Estado español. Sin embargo, en el referéndum que aprobó el Estatuto de Autonomía, que tuvo lugar el 25 de octubre de 1979, tan solo participó el 59,6 por cien, lo que deja ver claramente que no suscitó mucho interés. Adoptado el Estatuto de Autonomía, había que ponerlo en marcha, lo que se llevó a cabo bajo el ya muy conocido dirigente catalán Jordi Pujol, cuyo partido (CIU) ganó las elecciones el 20 de marzo de 1980.

5 A este respecto, véase el interesante comentario de SóRIA, J. M., «Las últimas horas de Companys», La Vanguardia, del 14 de octubre de 2010, con ocasión de su septuagésimo aniversario. Murió gritando con firmeza «Per Catalunya», y si ningún rencor.

6 Véase, www.ben.cat/estadistica/angles/dades/telec/ref/ref78/r22/htm [consultado: 18/08/2018]. Estos datos proceden del Ministerio del Interior español, tal y como han sido proporcionados por la Junta Electoral Central. En esta página figuran todos los datos correspondientes a cada comunidad autónoma. 
Es aquí donde ya empieza a construirse las bases jurídicas y políticas de lo que se ha denominado el «procès», y que fue publicado por el diario el «Periódico» de Barcelona el 28 de octubre de $1990^{7}$. Y es que Jordi Pujol, al mismo tiempo que se puso manos a la obra para construir una estructura estatal catalana, era un actor relevante en el Gobierno de Madrid, tanto con Felipe González como con José María Aznar. Cabe preguntarse si los distintos Gobiernos de Madrid eran o no conscientes de los riesgos en los que podían caer, aunque al margen de esta cuestión, lo que sí está claro es que hicieron gala de una gran ingenuidad, aunque ellos luego se hayan defendido invocando el principio de lealtad. Pero si los Gobiernos de Madrid podían ser ingenuos ¿Quid de los servicios de inteligencia españoles? ¿No sabían nada de lo que se estaba tramando en Cataluña tanto a nivel de la corrupción como en el ámbito político? El que fuera en su momento Presidente catalán del Partido socialista ya denunció en el Parlamento de Cataluña el famoso «tres por ciento» que las empresas que llevaban a cabo los trabajos públicos debían pagar al Gobierno catalán, pero ni el Gobierno Central ni la Fiscalía general del Estado movieron un dedo para indagar lo que todo el mundo se imaginaba ${ }^{8}$. A todo esto conviene añadir otro elemento importante: el adoctrinamiento feroz que se ha venido haciendo en favor de la independencia en las escuelas catalanas, en las que la palabra «España» estaba vetada, lo que ha traído consigo que incluso muchos inmigrantes hayan abrazado las tesis independentistas, como ha sido el caso del jefe de la policía catalana, Trapero, hoy en día investigado por varios delitos y considerado como un traidor no solo en su ciudad natal, la castellana Valladolid, sino en toda España.

Todo esto iba a traer consigo el deseo de reformar el Estatuto de Autonomía con el fin de ampliar el marco competencial del gobierno catalán, y contando en este caso con el apoyo del partido socialista español tanto a nivel regional como nacional. Pero lo más grave es que se llegó a esta peligrosa situación sin que los últimos Gobiernos de Madrid supieran comprender a donde les dirigía esta situación, contentándose con el famoso principio «apoyadme, Señores nacionalistas en Madrid, y podréis hacer lo que os plazca en Barcelona», colaborando así con la estrategia del propio «procès». Así las cosas, no es extraño que en este ambiente de pasividad gubernamental

7 A este respecto, ver: https://www.dolcacatalunya.com/2016/08/documento-prueba-jordi-pujoldiseno-prueses-1990/ [consultado: 12/08/2018].

8 Sobre esta cuestión, véase «Maragall acusa a CIU de corrupción y lo retira tras la amenaza de Mas de boicotear el Estatuto», El País, 25 de febrero de 2005. 
española, los partidarios de la huida hacia adelante aprovecharan la ocasión para impulsar un espíritu de reforma del marco jurídico autonómico con un objetivo claro que era el de ampliar los ámbitos competenciales del Gobierno catalán, algo imprescindible para afianzar la estructura política independentista catalana9.

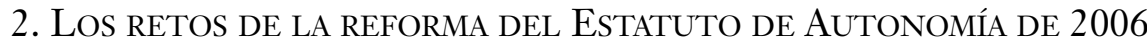
Y SUS NEFASTAS CONSECUENCIAS

A principios de este siglo XXI se comienza a ver un espíritu renovador del Estatuto de Autonomía de Cataluña, y este movimiento también es apoyado por el Partido Socialista Catalán, encabezado por Pascual Maragall. Las elecciones catalanas del 16 de noviembre de 2003 le dan ganador, y forma un gobierno de coalición con la separatista «Esquerra Republicana» de Cataluña e Iniciativa per Catalunya-Verds. Esta coalición ha salido del Pacto de Tinell, y su principal objetivo es la reforma del Estatuto de Autonomía. En esta aventura, la coalición también cuenta con el apoyo de CIU, ya dirigido por Artur Mas, pero sobre todo contará con el apoyo del nuevo jefe del Gobierno español, el socialista José Luis Rodríguez Zapatero, que gana las elecciones del 14 de marzo de 2004, después de los terribles ataques terroristas de origen yihadista del 11 de marzo, en el que murieron casi 200 personas y alrededor de 1.900 heridos.

España entra así en un camino peligroso sin saber exactamente a dónde va, pero cuenta con el apoyo del Gobierno socialista en Madrid, sin que éste tuviera ningún papel moderador, por no decir casi lo opuesto. Este craso error de José Luis Rodríguez Zapatero pesa y pesará siempre sobre él, ya que muchos analistas políticos españoles creen que él ha sido el único político español que siendo el Jefe de Gobierno en Madrid ha apoyado abiertamente el separatismo catalán, aunque no está claro si por ignorancia o por falta de visión. Conozco personalmente al ex presidente del Gobierno español, ya que vivió y estudió derecho en León, y pensamos que es sobre todo lo primero más que lo segundo, pero eso no le exime de una gran responsabilidad debido especialmente por apoyar el partido socialista español en el propio Parlamen-

9 Para mas detalles sobre estos aspectos, véase AYUSO, J., «Estrategia de construcción del enemigo español», El País, del 2 de diciembre de 2017. 
to español la reforma del Estatuto catalán aprobado el 30 de marzo de 2006, mientras que todos los diputados del partido separatista Esquerra Republicana se abstenían porque para ellos la reforma no iba demasiado lejos.

En cuanto al contenido de esta reforma, hay que recordar que las discusiones fueron intensas no solo sobre temas tales como la financiación en la región o la reivindicación nacionalista de los «derechos históricos» de Cataluña, sino también sobre aspectos como la cuestión de la laicidad en la enseñanza o sobre las lenguas co-oficiales (catalán y castellano), etc., tanto en el Parlamento catalán como después en el Congreso de los diputados en Madrid. Sin embargo, se llegó a un acuerdo rápidamente en el Parlamento catalán entre los partidos independentistas y el Partido Socialista Catalán para definir Cataluña como una «nación», aspecto este sumamente problemático, así como la creación de una circunscripción especial catalana para las elecciones al Parlamento Europeo. Este mismo debate tendría lugar más tarde en el Congreso de los Diputados español el 2 de noviembre de 2005, en el que el propio Presidente del Gobierno español, José Luís Rodríguez Zapatero se pronunció claramente a favor de la adopción de un nuevo Estatuto para Cataluña. Esta propuesta de nuevo Estatuto fue aprobado por 197 votos, incluidos los votos de los diputados socialistas, contra 146 que representaba los votos de los miembros del Grupo Popular, y una abstención, permitiendo así que el debate sobre el contenido del Estatuto en el Parlamento español tuviera lugar, aunque la cosa no fue fácil, ya que los partidos catalanes que habían adoptado el texto en el Parlamento catalán no pudieron ponerse de acuerdo sobre el contenido exacto del Estatuto.

Así las cosas, el Presidente del Gobierno español, Rodríguez Zapatero, para romper el punto muerto en el que estaban los partidos catalanes, negocia directamente con el líder de la oposición en Cataluña, Artur Mas, y llegan a un acuerdo tanto en el concepto de «nación» para Cataluña como en la financiación, pero que es rechazada por otros partidos nacionalistas catalanes. Por último, el nuevo Estatuto es aprobado por el Congreso de los Diputados español el 30 marzo de 2006 con el apoyo de la mayoría de los partidos españoles y catalanes, a excepción de los miembros del partido separatista Esquerra Republicana y los del pequeño Partido Vasco «Eusko Alkartasuna» que se abstienen, mientras que los diputados del Partido Popular votaron en contra. Aprobado en el Congreso de los Diputados, quedaba todavía la aprobación por referéndum en la Comunidad Autónoma de Cataluña que tuvo lugar el 18 de junio de 2006. El resultado fue de 73.23 por cien de los votos por el «sí», contra el 26,72 por cien para el «no», y 5,34 por cien que votó en «blanco». 
Este referéndum no generó un gran interés, como lo demuestra la baja participación que fue del 48,8 por cien, es decir, menos de la mitad ${ }^{10}$.

A pesar de la falta de legitimidad popular, se validó, ya que el Estatuto de 1979 no preveía un porcentaje mínimo de participación. Pero la reforma del Estatuto catalán no terminaría ahí, pues el Partido Popular presentó el 31 de julio de, 2006, un recurso ante el Tribunal Constitucional, abogando que aproximadamente la mitad de los artículos aprobados del Estatuto era inconstitucionales. La tarea para el Tribunal Constitucional no sería fácil, aunque después de cuatro años emitió una sentencia el 28 de junio de 2010, anulando catorce artículos del Estatuto de Autonomía de un total de 223, pero especialmente uno que reconoce el concepto de «nación catalana» a concepto que no estaba definido en el Estatuto, al tiempo que reconoce su valor histórico y cultural. Para el Tribunal la palabra «nación» fue, por tanto, interpretado como que el término podría dar lugar a una reivindicación de un Estado, siguiendo así la doctrina del «Estado-nación» dada por Ernest Renan en una conferencia en la Sorbona en 1882, y que ha sido la seguida por el Derecho internacional, en contraposición a la teoría objetiva, defendida por la doctrina alemana. Una vez anulado este concepto, el Estatuto ya quedó cojo para los independentistas, aunque el Tribunal también anuló otras disposiciones como la naturaleza «preferente» del catalán sobre el español, las relativas a las competencias del Defensor del pueblo catalán, así como el sistema de financiación ${ }^{11}$.

Una vez conocida la decisión del Tribunal Constitucional, hubo fuertes protestas en toda Cataluña, pero sobre todo en Barcelona, el 10 de julio del 2010, convocadas por «Omnium Cultural», cuyo líder, Jordi Cuixart, se encuentra actualmente en prisión. Tras la decisión del Tribunal Constitucio-

10 Sobre esta reforma, véase JulIANA RICART, E., La España de los pingïinos. Una visión antibalcánica del porvenir español: la concordia es posible, Destino, 2006, 222 p. El autor narra las peripecias políticas del momento con cierto optimismo, aunque por el momento parece que se ha equivocado, como oros muchos analistas.

11 A este respecto, véase DE CARRERA, F., «Cataluña tras la sentencia del Estatuto», en: https.www. letraslibres.com/mexico-españa/cataluna-tras-la-sentencia-del-estatuto [consultado: 11/08/2018]. Este Catedrático de Derecho constitucional de la Universidad Autónoma de Barcelona lleva a cabo un estudio riguroso de los efectos que esta sentencia podría tener en España y en Cataluña, al considerar que la reforma estatutaria desbordaba ampliamente los límites constitucionales. Para superar estas dificultades, aboga por una reforma constitucional de índole federal, en la que Cataluña participe junto a las demás comunidades autónomas en la adopción de decisiones estatales a través del Senado, de la Conferencia de Presidentes, de las Comisiones mixtas EstadoComunidades autónomas y de los demás instrumentos propios del federalismo. Puede que no le falte razón en ofrecer estas propuestas, pero un poco difíciles de llevar a cabo, ya que los líderes independentistas no parece por el momento que renuncien a sus pretensiones identitarias. 
nal, se abre así una nueva etapa en el proceso independentista, en el que la confrontación estará a la orden del día, y todo esto a pesar del apoyo que el Partido Socialista Catalán dio a la reforma del Estatuto catalán. En nuestra opinión, la sentencia del Tribunal Constitucional no sólo es un gran revés para los grupos separatistas, sino también, y sobre todo, para el propio Gobierno español encabezado por José Luis Rodríguez Zapatero, que fue el que abrió la caja de pandora de la independencia catalana tan pronto como comenzó a apoyar la reforma del Estatuto. A pesar de las serias y fieles advertencias que se le hicieron, el Presidente Zapatero siguió su camino sin escuchar a nadie, generando así la crisis más grave que ha conocido España desde la Guerra Civil, aunque el presidente Zapatero siguió su camino sin escuchar nada a nadie.

\section{Pero, ¿Puede Cataluña reclamar la independencia? ALGUNOS BREVES COMENTARIOS A NIVEL JURÍDICO INTERNACIONAL}

La decisión del Tribunal Constitucional de 28 de junio 2010 corta de raíz las ambiciones políticas de los separatistas, que habían encontrado en el concepto de «nación» una especie de Arca de Noé en la que se pudiera anclar una realidad nacional más que dudosa. Pensaban que sería reconocido ese concepto como algo legal en virtud de las decisiones políticas adoptadas por algunos partidos, incluido el Partido Socialista, que estaba en el poder con el presidente Rodríguez Zapatero, y a quien le faltó visión para apercibir el problema. Frente a esta tragicomedia el Tribunal Constitucional cortó de raíz las expectativas separatistas señalando claramente que el concepto de «nación», al menos tal y como se entendía, era incompatible con el artículo 2 de la Constitución española, que proclama «la indisoluble unidad de la nación española, patria común e indivisible de todos los españoles». Cabe señalar que muchas otras constituciones contienen disposiciones similares, y por lo tanto no es una exclusividad española. Sin embargo, la pregunta clave es la siguiente: ¿Permite el Derecho internacional el derecho a la libre determinación de los pueblos no coloniales como es el caso de Cataluña?

\subsection{Algunos comentarios sobre el derecho de autodeterminación}

Como se sabe los líderes independentistas catalanes reivindican el derecho a la autodeterminación de la población de esta región, y piden un referéndum para que la población de este territorio decida. Esta reivindicación no solo choca 
frontalmente con el marco constitucional español, sino que el propio Derecho internacional no lo recoge salvo para los pueblos coloniales. En efecto, es evidente que el principio que consagra el derecho de libre determinación de los pueblos, aplicado extensa e intensamente a los pueblos coloniales desde la Segunda Guerra Mundial, se ha convertido en una norma de Derecho internacional positivo, y más en concreto consuetudinaria, por lo tanto de carácter general, al reunir los dos elementos precisos para la conformación de una costumbre: numerosas resoluciones de las Naciones Unidas, adoptadas por unanimidad, sin votos en contra o por abrumadoras mayorías sobre casos concretos y sobre problemas o enfoques generales del tema; la práctica de los Estados con colonias, que han procedido, acatando estas resoluciones, a descolonizar sus antiguas posesiones; y la incorporación de algunas de las disposiciones derivadas del derecho a la libre determinación en tratados internacionales universalmente «consentidos». Todos estos hechos analizados en su conjunto permiten sustentar la existencia de una práctica general, uniforme y constante realizada con el convencimiento de su obligatoriedad jurídica. Una interpretación de esta naturaleza se ve considerablemente reforzada de un lado por ser casi la unanimidad de la doctrina que ha analizado esta práctica y, de otro y sobre todo, porque la Corte Internacional de Justicia (CIJ) ha ratificado la naturaleza jurídico-consuetudinaria del derecho de los pueblos coloniales a su libre determinación ${ }^{12}$.

Más aún, nadie pone en duda hoy que esta norma forma parte del Derecho internacional imperativo, siendo pues de fundamental importancia para la comunidad internacional en su conjunto. La CIJ y la Comisión de Derecho Internacional (CDI) lo han afirmado resueltamente ${ }^{13}$, lo que implica, entre otras consecuencias, que su violación grave supondrá para su autor el régimen de responsabilidad particular que, según el Proyecto de artículos sobre la responsabilidad del Estado por hechos internacionalmente ilícitos aprobado por la Comisión en agosto de 2001 y endosado por la Asamblea General de Naciones Unidas

12 Dictamen consultivo de 21 de junio de 1971, asunto de Namibia, párrafo 52 (CI7 Recueil 1971, p. 31); dictamen consultivo de 16 de octubre de 1975, asunto del Sahara occidental, párrafos 5458 (CI7 Recueil 1975, pp. 31-33).

13 Sentencia de 5 de febrero de 1970, párrafos 33-34, asunto de la Barcelona Traction, CIf Recueil 1970, p. 32; sentencia de 30 de junio de 1995, párrafo 29, asunto de Timor Oriental, CI7 Recueil 1995, p. 102. Por lo que a la CDI se refiere, comentarios 4 y 5 al artículo 40 de su Proyecto sobre la responsabilidad del Estado por hechos internacionalmente ilícitos, Informe de la CDI sobre su $53^{\circ}$ período de sesiones (23 de abril a 1 de junio y 2 de julio a 10 de agosto de 2001). Documentos oficiales de la Asamblea General, $56^{\circ}$ período de sesiones. Suplemento no 10 (56/10), Nueva York, 2001, pp. 306-307. 
en diciembre de ese mismo año ${ }^{14}$, corresponde a quienes cometan hecho ilícitos de tamaña naturaleza ${ }^{15}$.

Claro que hay elementos recientes que plantean la interrogante de si la norma que consagra el derecho de libre determinación de los pueblos coloniales no está perdiendo impulso. La resistencia de algunos Estados, interesados al parecer (como EEUU y Francia) en que el principio de libre determinación no se aplique al caso del Sáhara Occidental del mismo modo que ha venido siéndolo desde la Segunda Guerra Mundial no es la única frustración: también se puede mencionar la incongruencia de la CIJ de calificar al citado principio, en el asunto de Timor Oriental (1995), de obligación erga omnes para luego no sacar las pertinentes consecuencias procesales ${ }^{16}$; y otras posiblemente, conectadas con las «modulaciones» introducidas a la postre en los Proyectos de artículos que la Comisión de Derecho Internacional había aprobado en relación con los crímenes contra la paz y seguridad de la humanidad y respecto de la responsabilidad del Estado por hechos internacionalmente ilícitos ${ }^{17}$.

Pero ¿hay otros pueblos, a partir de los coloniales, que pudieran tener también el derecho de autodeterminación? La respuesta es positiva, pero no como la de los pueblos coloniales y de un ámbito muy restringido, pues dejando al margen el tema de los pueblos indígenas, cuya problemática es muy concreta ${ }^{18}$, para que ello sea posible, es necesario que se den una serie de condiciones muy

14 Resolución 56/83, de 12 de diciembre de 2001.

15 Para un análisis detallado del mismo ver GutiÉRrez EsPADA, C., La responsabilidad internacional (consecuencias del hecho ilícito), Murcia, Diego Marín Librero-Editor, 2005.

16 Ver GutiÉrRez EsPadA, C., «¿Actio popularis en Derecho Internacional?», Estudios de Derecho Internacional en Homenaje al Profesor Ernesto 7. Rey Caro, Marcos Lerner-Editora Córdoba, Drnas Zlata-Lerner Marcelo (ed.) y Drnas Zlata (coord.), Córdoba (República Argentina), 2002, tomo I, pp. 568 y ss.

17 SáENZ DE SANTAMaría. P.A., «La libre determinación de los pueblos en la nueva sociedad internacional», Cursos Euromediterráneos Bancaja de Derecho Internacional, 1997, I, pp. 160-165.

18 A este respecto, conviene recordar que España se ha vinculado muy recientemente al Convenio sobre pueblos indígenas y tribales en países independientes (1989), en el que se aborda y pone al día un estatuto jurídico básico para colectivos de esa naturaleza, respecto de los que se reconoce sus «aspiraciones... a asumir el control de sus propias instituciones y formas de vida y de su desarrollo económico y a mantener y fortalecer sus identidades, lenguas y religiones», pero siempre «dentro del marco de los Estados en que viven». Ver párrafo quinto de su Preámbulo (Convenio número 169 de la OIT, hecho en Ginebra el 27 de junio de 1989, y ratificado por España el 29 de enero de 2007, BOE 8/III/1989). En relación con la actual situación de los pueblos indígenas vid. TORRECUadrada García-Lozano, S., Los pueblos indígenas en el orden internacional, Madrid, Dykinson, 2001; Oliva MarTínez, J.D., El Fondo para el Desarrollo de los Pueblos Indígenas de América Latina y el Caribe, La Paz (Bolivia), Foro Indígena, 2003; Mariño MenÉndeZ, F.D.; Oliva MarTíneZ, J.D. (eds.), Avance en la protección de los derechos de los pueblos indígenas, Madrid, 2004. 
estrictas. En efecto, El derecho de libre determinación de los pueblos nacionales no coloniales les protege de no ser excluidos del gobierno del Estado ni perseguidos por su raza, credo o color. Por lo tanto, ni independencia ${ }^{19}$ ni un régimen de autonomía sino derecho a ser tratado en pie de igualdad, de estricta igualdad, con el resto de la población del Estado. Algunos lo sintetizan afirmando que los pueblos nacionales que viven en un Estado soberano tienen un derecho de autodeterminación interna pero no externa. Este fue el caso del Acuerdo de paz de Belfast de 1998, que busca la reconciliación de las dos Irlandas y puede decirse que ha tenido un cierto éxito ya que en él se consagra la plena realización del derecho de autodeterminación interna de Irlanda del Norte, pero en ningún caso el de autodeterminación externa ${ }^{20}$.

Así las cosas, en el caso de los pueblos no coloniales, o no sometidos a una ocupación extranjera o un régimen racista, el derecho de los pueblos a su libre determinación solo da a estos derecho a participar en pie de igualdad, sin discriminación por su raza, credo o color. Un Estado que respeta este mínimo cumple con el Derecho internacional en cuanto a la libre determinación de sus pueblos, en virtud del párrafo séptimo del principio de libre determinación de los pueblos de la Declaración aneja a la Resolución 2625 (XXV), de 24 de octubre de $1970^{21}$, reproducido prácticamente por la Resolución 50/6, de 24 de octubre de 1995, de la Asamblea General, viendo así protegida su integridad territorial por esta cláusula de salvaguardia contra eventuales secesiones ${ }^{22}$.

19 La mayoría de la doctrina, con base en la práctica estatal, se pronuncia negativamente sobre un derecho de secesión de los pueblos no coloniales a tenor de la resolución 2625 (XXV) CASSESE, A., Self-determination of Peoples. A Legal Reappraisal, Cambridge, Grotius Publications, Cambridge University Press, 1996, $2^{a}$ reimp. , pp. 123-124; ANDRÉs SÁENZ DE SANTAMARÍA, P., «La libre determinación...», op. cit., p. 187; REMIRO BRoTONS, A., «Desvertebración del Derecho internacional en la sociedad globalizada», Cursos Euromediterráneos Bancaja de Derecho Internacional, V, 2001, pp. 110-120; EUDES, M., «Retour sur une réussite passée inaperçue: L'Accord de Belfast et la nouvelle lecture du droit à l'autodétermination», Révue générale de droit i nternational public, $\mathrm{n}^{\circ}$ 3, 2006, pp. 633 y ss.; y MANGAS MARTín, A., «El 'plan Ibarretxe' se estrella contra el Derecho internacional», El Mundo, 10 de octubre de 2007.

20 Ver EudEs, M., «Retour sur une réussite...», op. cit., pp. 631-646.

21 «Ninguna de las disposiciones de los párrafos precedentes se entenderá en el sentido de que autoriza o fomenta acción alguna encaminada a quebrantar o menoscabar, total o parcialmente, la integridad territorial de los Estados soberanos e independientes que se conduzcan de conformidad con el principios de la igualdad de derechos y de la libre determinación de los pueblos antes descrito y estén por tanto, dotados de un Gobierno que represente a la totalidad del pueblo perteneciente al territorio, sin distinción por motivos de raza, credo o color».

22 En su párrafo 1 dedicado al tema de la paz, la Declaración reafirma el derecho de libre determinación de los pueblos y reproduce el párrafo séptimo del contenido en este principio en la Declaración de 
Una interpretación de esta naturaleza, defendida con vigor doctrinalmente ${ }^{23}$, parece confirmada por el Tribunal Supremo de Canadá en su Declaración de 20 de agosto de 1998 a propósito del asunto de Québec. En esta decisión, y citando tanto la Resolución 2625 como la 50/6 en los pasajes aquí mencionados, el Tribunal acepta que los pueblos no discriminados y que están representados sin distinción alguna respecto de los demás que integran el Estado por el Gobierno del mismo ven respetado su derecho de autodeterminación, y queda garantizada la integridad territorial del mismo, excluyéndose, pues, un derecho unilateral a la secesión o a la independencia que solo en el caso de los pueblos coloniales u oprimidos por una ocupación militar extranjera o un régimen racista y, acaso, los pueblos discriminados y no representados por el Gobierno del Estado sin distinción alguna...» lo tendrían ${ }^{24}$. El profesor Cassese precisa que la cláusula de salvaguardia con que se cierra el párrafo $7^{\circ}$ del principio sobre libre determinación detallado en la Resolución 2625 (XXV) exige tres requisitos distintos para que un pueblo que vive en el seno de un Estado pueda legítimamente invocar su derecho a la secesión:

«Thus, denial of the basic right of representation does not give per se the right of secession. In addition, there must be gross breaches of fundamental human rights, and, what is more, the exclusion of any likelihood for a possible solution within the existing State structure» ${ }^{25}$.

De este texto se deduce además que el Derecho internacional no parece exigir ni con mucho que los Estados otorguen la concesión de un «estatuto de autonomía», y menos que este sea «amplio y considerable».

1970 alterando sólo su parte final: «de un Gobierno que represente a la totalidad del pueblo perteneciente al territorio, sin distinción alguna».

23 Como, sin ánimo de exhaustividad, CASSESE, Self-determination..., op. cit., pp. 119 ss.; MARIÑo MENÉNDEZ, F., «Naciones Unidas...», op. cit., p. 105; Castellano, J., International Law and Selfdetermination, La Haya-Boston-Londres, Nijhoff, 2000, p. 40.

24 Supreme Court of Canada: Reference to secession of Quebec, August 20 1998, párrafos 126139 (en International Legal Materials, XXXVII, 1998, nº 6, noviembre, pp. 1.371-1.374); repárese en las dudas que el TS de Canadá tiene respecto de esta tercera excepción (ver sobre todo los párrafos 135 y 138 de su declaración). Sobre esta decisión ver. RODRÍGUEZ-ZAPATA PÉREZ, J., «Autodeterminación y Constitución», Revista General de Legislación y furisprudencia, III época, n ${ }^{\circ}$ 1, enero-febrero 1999, pp. 37-38 y 43 y ss.; HaLjan, D. P., «Negotiating Québec Secession», Révue belge de droit international, XXXI, nº 1, 1998, pp. 198-199; BAYEFSKY, A. F., Self-determination in International Law. Québec and Lessons Learned, La Haya, Kluwer, 2000. Sabido es que la «doctrina» sentada por el TS de Canadá ha sido incorporada por el Gobierno en la llamada «ley de la claridad».

25 Self-determination..., op. cit., pp. 119-120. 
Pero el caso de Kosovo, primero, y ahora la crisis catalana, al menos tal y como la están describiendo los líderes independentistas catalanes, e incluso el propio Gobierno autonómico catalán, parecen incluso dar alas a las tesis reduccionistas que ponían en duda el reconocimiento de un derecho de secesión unilateral para los pueblos-minoría incluso en el caso de no verse representados sin distinción alguna en el Gobierno del Estado. El TS de Canadá considera «poco claro que esta tercera propuesta refleje actualmente un estándar bien establecido de Derecho internacional $\gg^{26}$. Esta es la conclusión a la que llegan algunos autores que se oponen a lo que se ha denominado hipótesis de la «secesión-remedio», que en su opinión no es admitida por el Derecho positivo ${ }^{27}$. Hay que reconocer que muchos partimos de la premisa de que una interpretación tanto de la Resolución 2625 (1970) como, posteriormente, de la Resolución 50/6 (1995), favorable al reconocimiento del derecho de secesión de los pueblos dentro del Estado despreciados y marginados de la solicitud o perseguidos sistemática y generalizadamente, se ve muy duramente puesta a prueba sobre todo cuando los que dicen que son reprimidos por el Estado «represor», no se dan cuenta, ni admiten que son ellos los principales represores.

\subsection{El Tribunal Constitucional español rechaza de plano la autodeterminación catalana}

Tal y como hemos comentado en las anteriores páginas, el derecho a la autodeterminación está reservado, pues, sólo para los pueblos coloniales, no para los pueblos que forman parte de un Estado, siempre que respeten los derechos fundamentales, las libertades públicas y los derechos de las minorías culturales o lingüísticas. La doctrina internacionalista mundial es pues categórica a la hora de reconocer el derecho a la libre determinación de los pueblos coloniales, tal y como recogen la Resolución 1514 (XV) de 1960, la Resolución 1541 (XV) de 1960, así como la Resolución 2625 (XXV) de 1970.

26 Ver párrafo 135 de la Sentencia sobre Québec.

27 CoRTEn, O., «A propos d'un désormais 'classique': Le droit à l'autodetermination en dehors des situations de décolonisation, de Théodore Christakis», Revue belge de droit international, XXXII, $\mathrm{n}^{\circ} 1$, 1999, pp. 340-344; de la misma opinión, KoHEN, M.G., «L'emploi de la force et la crise de Kosovo: Vers un nouveau désordre juridique international», Révue belge de droit international, XXXII, $\mathrm{n}^{\circ} 1,1999$, pp. 127-129. 
Estas resoluciones de la Asamblea General de las Naciones Unidas, así como muchas otras, son claras a este nivel, y no plantean ningún problema de interpretación. Cuando los pueblos no son coloniales, es la integridad territorial lo que prevalece, siempre y cuando se respeten los derechos mencionados anteriormente.

Para que un pueblo no colonial pueda obtener la independencia, es necesario que toda la población del Estado se pronuncie en un referéndum sobre esa posibilidad, y que se apruebe, según ha señalado el Tribunal Supremo de Canadá en 1998 en su conocida decisión relativa al Quebec. Dicho esto, la cosa está clara: como el Derecho internacional, no reconoce a estos pueblos el derecho a la libre determinación, la única vía legal es el derecho a la libre determinación interna, que hoy no reconoce el derecho a la independencia pero sólo la garantía, más o menos desarrollada, donde se respeten sus derechos culturales, lingüísticos y religiosos, así como los derechos humanos fundamentales de un marco democrático. Para avanzar hacia la independencia, es necesario además el consentimiento de toda la población del país, en este caso el pueblo español, porque sólo él es el depositario de la soberanía nacional previsto en el artículo 1.2 de la Constitución. Esto es precisamente lo que señala el Tribunal Supremo de Canadá mencionado en su sentencia de $1998^{28}$.

Es decir, si el Gobierno español quisiera hacer un acuerdo con las autoridades catalanas para permitir la independencia o preparar un camino a seguir para lograr este objetivo, se debe contar con la aprobación de todos los españoles. Esto es lo que prevén la mayoría de las Constituciones de los Estados democráticos, poco importa que sean centralizados, descentralizados o federales. El caso de la creación del Cantón del Jura en Suiza en la mitad de la década de los setenta es un buen ejemplo de ello. Sin embargo, jurídicamente hablando, no hay que confundir el derecho a la independencia o a la secesión

28 Desde que el Tribunal Supremo de Canadá adoptara esta sentencia, han sido numerosos los estudios llevados a cabo sobre esta cuestión. Lo mismo ha ocurrido en España, como lo demuestra la publicada titulada La autodeterminación a debate, Presentación de Juan José Solozábal, Fundación Pablo Iglesias, 2014, 224 p. En este estudio, en el que participan nueve autores se tratan temas relacionados con los planteamientos independentistas (incluidos el problema catalán y el escocés) y el alcance del derecho de autodeterminación. Sobre el tema catalán, véase AGUADO RENEDO, C., «Sobre un eventual referéndum consultivo catalán en el proceso soberanista», pp. 9-29; y en relación con Escocia, LóPEZ BASAGUREN, A., «Escocia y el referéndum por la independencia: algunas enseñanzas», pp. 109-122. Ver también Cuadernos de Alzale, Revista vasca de la cultura y las ideas, 2013, núms. 46-47, con doce estudios sobre este tema. 
con el derecho a decidir, un concepto de moda en España, reivindicado por algunas personas más cercanas a la política que a la ley, tratando de confundir a la opinión pública en lugar de informarla de buena fe. En este contexto, y a pesar de algunas opiniones que circulan por Internet y Wikipedia, la Constitución española es clara, y la doctrina del Tribunal Constitucional también.

De hecho, de acuerdo con la decisión 42/2014 de 25 de marzo de 2014, en la que se ocupa de un recurso presentado por el Gobierno contra la resolución del Parlamento catalán 5 / X, de 23 de enero de 2013, que aprueba la Declaración de soberanía y el derecho a decidir del pueblo de Cataluña, ${ }^{29}$ el Tribunal Constitucional lleva a cabo una serie de consideraciones claras y precisas que rechazan de plano el derecho de autodeterminación de Cataluña. En efecto, el Tribunal Constitucional español considera que la Resolución 5 / X del Parlamento catalán, a pesar de su carácter político marcado, también tiene un carácter legal, y produce efectos de esta naturaleza, es decir jurídicos, ya que da poderes específicos de la soberanía a las instituciones catalanas que son superiores a los que proceden de la autonomía reconocida por la Constitución a las nacionalidades que integran la Nación española. Sin embargo, el Tribunal desarrolla aún más esta afirmación en el párrafo 3 de sus motivaciones jurídicas cuando aborda los siguientes conceptos: a) El contenido del primer principio de la resolución, cuyo título es «soberanía», informa que «el pueblo de Cataluña tiene por razones de legitimidad democrática, un carácter político y sujeto soberano; y b) el Tribunal comenta el contenido de las referencias que se hacen al derecho a decidir de los ciudadanos de Cataluña».

Siguiendo estas dos directrices, el Tribunal observa que la calidad del pueblo soberano de Cataluña lo es solamente para los poderes constituidos de conformidad con el derecho a la autonomía reconocido por la Norma Fundamental (Constitución), porque «no es el titular del poder soberano, que es exclusivo de la nación Española constituida en Estado, y la Constitución parte de la unidad de la nación española que se constituye como Estado social y democrático de derecho, cuyos poderes emergen del pueblo español que es en el que reside la soberanía nacional». Todo este razonamiento se basa en dos pilares fundamentales del orden constitucional español: a) El artículo 1.2, que proclama el principio según el cual la soberanía nacional reside en el pueblo español; y b) la unidad de la Nación española proclama-

29 Para el texto de esta decisión, véase el Boletín Oficial del Estado, BOE-A-2014-3885, de 04.10.2013. 
da en el artículo 2. Y el Tribunal Constitucional añade además que todo el sistema de las Comunidades Autónomas españolas tiene su base jurídica en la soberanía nacional del pueblo español, debido a que la soberanía «no es el resultado de un pacto entre las entidades territoriales históricas que conservan derechos anteriores a la Constitución y superiores a ella, sino que se debe a una norma del poder constituyente que se impone sin que se pueda pretender que determinadas situaciones históricas anteriores se queden fuera del marco constitucional. Es precisamente por esta razón por lo que no se puede confundir Escocia con Cataluña, como ya lo hemos apuntado en 2012 en el periódico madrileño La Razón ${ }^{30}$, y tampoco autonomía con soberanía. Por esta razón, el Tribunal señala que una Comunidad autónoma no puede convocar de manera unilateral un referéndum de autodeterminación para decidir sobre su integración en España», recordando al mismo tiempo que a esta misma conclusión llegó el Tribunal Supremo de Canadá en su sentencia de 20 de agosto de 1998. Por consiguiente, el Tribunal Constitucional ya advirtió que el referéndum que iba a celebrarse el 9 de noviembre de 2014 era ilegal, así como el que tendría lugar más tarde, es decir, el de 1 de octubre de 2017.

Otra cuestión completamente diferente a nivel jurídico, y que no conviene confundir, es el derecho a la independencia o a la secesión con lo que se llama el derecho a decidir, un derecho que también se incluye en la resolución, y que el Tribunal respalda porque no se proclama con carácter independiente o directamente relacionado con la declaración de soberanía del pueblo catalán, ni como un derecho a la libre determinación, que no se reconoce en la Constitución, y tampoco como una atribución de soberanía, sino como una simple aspiración política a la que se puede llegar recurriendo solo a un camino que esté de acuerdo con el Derecho constitucional, y respetando los principios de la «legitimidad democrática», «pluralismo»y «legalidad». Esta decisión del Tribunal Constitucional español establece el camino a seguir para elegir o el camino de la legalidad y la democracia, o el de la ilegalidad con todos sus efectos. Parece que algunos catalanes han elegido este último.

30 Ver: http://www.larazon.es/historico/4911-por-que-cataluna-no-es-escocia-por-romualdo-bermejoRLLA_RAZON_494974. Este artículo ha sido publicado el 16 de octubre de 2012. Ver también el artículo «Las falacias independentistas de Escocia y de Cataluña», publicado como editorial en el periódico El Mundo (Madrid) del 20 de marzo de 2017. 


\section{LA CRISIS CATALANA EN LA ACTUALIDAD: LOS REFERENDOS Y LAS DECLARACIONES UNILATERALES DE INDEPENDENCIA}

Hoy en día, sabemos, al menos en España, que muchos catalanes han seguido el camino de la desobediencia a las resoluciones judiciales y a otros organismos españoles, a pesar de las advertencias que de manera reiterada se les ha hecho. Uno de los primeros pasos dados por el camino de la ilegalidad corresponde al anterior Presidente Artur Mas, cuando convocó el referéndum del 9 de noviembre de 2014, siete meses después de la decisión del Tribunal Constitucional adoptada el 25 de marzo de 2014, y que acabamos de comentar. Este es el primer referéndum de independencia que lanza el proceso de creación de un «Estado» catalán, que debería terminar en el nacimiento de una República catalana, a más tardar, en 2017, siempre según los líderes que iniciaron este proceso, algunos de ellos ya encarcelados.

En esta consulta ilegal, que después será simplemente una consulta no referendaria, después de que el Tribunal Constitucional aceptara el recurso presentado por el Gobierno español en contra de este referéndum, que posteriormente será anulado por la decisión 31/2015 del 25 de febrero 2015, los votantes debían responder a las dos preguntas siguientes: «¿Quiere que Cataluña sea un Estado? En caso afirmativo, ¿quiere que Cataluña sea un Estado independiente? «Cabe destacar que la participación fue muy baja, ya que sólo participaron alrededor de 35 por ciento del electorado catalán, y el 80 por ciento votó por sí. Como el referéndum era ilegal, algo que ya lo había dicho el Tribunal Constitucional en la sentencia precitada ${ }^{31}$, el Presidente Artur Mas fue condenado por el Tribunal de Justicia de Cataluña el 11 de marzo de 2017 a una pena de prohibición para ejercer funciones públicas por dos años, tanto a nivel municipal, regional o estatal.

Era el primer aviso serio de los tribunales españoles al reto independentista catalán. Pero el ímpetu independentista no se iba a detener ahí, y empieza a plantearse una cierta locura reivindicativa frente a la cual el Gobierno de Madrid muestra una ignominiosa pasividad, como si el asunto que afectaba a la propia estructura política nacional, como dijo el Tribunal Constitucional, no fuera con él. A este respecto, la pasividad política del Gobierno de Rajoy es

31 Todos los medios informativos se ocuparon del caso, aunque solo queremos destacar a este respecto los dos artículos de María Jesús Cañizares en el diario $A B C$ de Madrid: «Artur Mas consuma su desafío y convoca la consulta del 9-N», del 27 de noviembre de 2014; y «La imposible legalidad de la Consulta de Artur Mas», del 12 de diciembre de 2014. 
grandiosa, al dejar al movimiento secesionista campar a sus anchas, dejando a los españoles de Cataluña solos ante el peligro. Este era el panorama cuando se celebran las elecciones catalanas el 27 de septiembre de 2015, en las que los partidarios de la secesión ganan las elecciones. Así las cosas, y con el poder en sus manos, el Gobierno catalán va a comenzar a establecer una hoja de ruta muy activa, sobre todo una vez que el ya famoso, Carles Puigdemont, periodista de profesión, llega a la Presidencia el 12 de enero de 2016. Asentado en el poder, y pensando incluso en utilizar las bayonetas llegado el caso, Carles Puigdemont, que muestra una imagen de grandeza digna de otras épocas, arrastra a su proyecto político fuerzas diversas tanto de la burguesía catalana como del mundo obrero, utilizando el lema «España nos roba».

Consigue así abrir un frente político muy activo y al mismo tiempo muy agresivo, ya que aquellos que no comparten sus opiniones son considerados automáticamente como enemigos, o incluso traidores. Comienza así una verdadera división política y social en la sociedad catalana que persiste y que incluso está empeorando, como se sabe, pues consiguió abrir vías de ruptura con todo lo que representa España, sus valores y su cultura. Es más no solo se muestra crítico con España a nivel político, sino que acusa a la sociedad española y al orden jurídico español de no ser democráticos, tildando al pueblo español de franquista y de fascista. En este ambiente, el ya Presidente catalán anuncia el 9 de junio de 2017 la convocatoria de un referéndum de autodeterminación para el primero de octubre.

Frente a este nuevo desafío, el Gobierno español reacciona y declara inconstitucional e ilegal el referéndum. Sin embargo, el 6 de septiembre, el Parlamento catalán lanza un nuevo reto para el Gobierno español y los tribunales mediante la adopción de la ley que organiza la votación en el referéndum. Un día después, el Tribunal Constitucional ordena la suspensión a título de medida preventiva, y el 17 de octubre, ya después de la consulta, la declara nula e inconstitucional en una sentencia muy dura aprobada por unanimidad. Además, la Fiscalía española comienza a trabajar y ordena a la policía controlar, y eventualmente también actuar en contra de cualquier autoridad, funcionario o incluso particulares con el objetivo de impedir la celebración del referéndum ilegal. El enfrentamiento entre el Gobierno Central y los separatistas catalanes va a continuar hasta el mismo 1 de octubre.

Así, el Tribunal Constitucional impuso por unanimidad el 21 de septiembre, duras multas (12.000 euros por día) al brazo derecho del vicepresidente, Oriol Junqueras, aún en prisión, así como al secretario general de la Vicepresidencia, Josep Maria Jové, y a siete miembros de la comisión electoral, mien- 
tras que los quince miembros de las comisiones electorales territoriales fueron multados con seis mil euros por día. Estas multas debían ser pagadas todos los días hasta que los responsables probaran ante el Tribunal que habían anulado todas las resoluciones adoptadas. Del mismo modo, también tuvieron que invalidar las medidas adoptadas que no respetaran la suspensión del referéndum.

Así las cosas, estas multas comienzan poco a poco a hacer mella entre los condenados, que empiezan a abandonar sus puestos. Siguen a la letra el dicho catalán de «el dinero es el dinero», o lo que es lo mismo: «La pela es la pela». Sin embargo, todas estas medidas no iban a ser suficientes para paralizar la carrera hacia el referéndum, a pesar de la llegada de varios miles de policías venidos de toda España a Cataluña. Estos refuerzos permitirían cerrar la mitad de los centros de votación el día anterior, es decir, el 30 de septiembre, pero a pesar de esto, y en gran parte debido a la pasividad o incluso la traición de los líderes de la policía catalana, hoy suspendidos de su cargo y acusados por la justicia española, el referéndum ilegal se llevaría a cabo solo para algunos catalanes en una atmósfera de caos y confusión, pero sin cumplir con las normas y garantías de un Estado democrático normal.

Las imágenes de la policía española golpeando a algunos manifestantes para impedir la votación, prohibida por la justicia española, recorrieron los medios audiovisuales del mundo sin saber que en la mayoría de los casos eran falsas. En cuanto a los heridos, algunas agencias de noticias hablaban de 800/900, pero no muertos y sólo tres hospitalizados, una cosa milagrosa... Sin embargo, el diario «Le Monde», mucho mejor informado de lo que estaba sucediendo en la zona, solo habló de 85 heridos $^{32}$. La cuestión planteada en el referéndum era la siguiente: «¿Quiere que Cataluña sea un Estado independiente en forma de república?» El resultado de la votación, aunque es difícil de establecer debido a las irregularidades cometidas, según lo que los organizadores dijeron fue que alrededor del 43 por ciento participó en el referéndum, y que casi el 90 por ciento votó por el sí.

32 Sobre esta cuestión, la prensa internacional se volcó de lleno, obviamente, a la hora de comentar este acontecimiento. Para un repaso de esa prensa y cómo veían el desarrollo del referéndum hacia las 14 horas, ver lo que recoge eldiario.es en: https://www.eldiario.es/restreador/prensamundial-vuelve-ojos-catalunya_6_69264073.html [consultado: 10/08/2018]. Este diario señala que a esa hora Le Monde contabilizaba tan solo 38 heridos. Unos días más tarde, el 6 de octubre, el Periódico de Barcelona, publicaba un artículo con el título «Le Monde afea las imágenes tramposas del referéndum en Catalunya», en donde se pone de manifiesto la manipulación informativa de 900/1000 heridos, salvo que se considere «herido» coger del brazo para retirar a un manifestante protector de las urnas... 
En cuanto a la consulta, queremos añadir el siguiente comentario. Un referéndum es una cosa muy seria, ya que requiere, tanto legal como políticamente, un procedimiento que sea consistente con la naturaleza del sujeto que se somete a votación. Un referéndum de este tipo no se prepara de un día al otro, porque una de las cuestiones a tratar, y no es la menos importante, es la determinación del censo electoral. Pero está claro que el referéndum ha fallado a las expectativas democráticas, tanto en el fondo como en la forma. El caso del referéndum de Montenegro de separarse de Serbia, que se llevó a cabo el 21 de mayo de 2006 es, sin embargo, muy diferente, porque jurídicamente hablando la secesión se incluyó en la Constitución, y el procedimiento también requería que para la separación sería necesario al menos el 50 por ciento del electorado, y se obtuviera al menos 55 por ciento de los votos.

Así pues, en el referéndum de Montenegro, la participación fue del 86,3 por ciento, de los cuales el 55,4 por ciento votó que sí. Si comparamos esto con la consulta del 1 octubre en Cataluña es fácil ver las diferencias. De hecho, si mencionamos también el procedimiento utilizado es porque nos parece mucho más razonable el utilizado en el caso de Montenegro, y además lo hacemos también para recordar que mientras que en el fondo los dos casos son muy diferentes, el procedimiento utilizado en el caso de Montenegro parece seguir a la letra la Ley canadiense del año 2000 adoptada para aclarar el dictamen del Tribunal Supremo de 1998, que establece algunos criterios que deben cumplirse estrictamente en un referéndum de autodeterminación, entre los que se incluyen una mayoría cualificada, no una mayoría simple, por no hablar de otros criterios que ya hemos analizado anteriormente. Los separatistas catalanes, entre ellos algunos compañeros universitarios, a menudo recurren al caso de Quebec, a pesar de que los independentistas del Quebec perdieron los dos referendos que se hicieron, pero no quieren escuchar o seguir las opiniones del Tribunal Supremo de Canadá, lo que es completamente extraño $0^{33}$.

Dicho esto, hay que señalar también que muchas instituciones habían advertido a los independentistas catalanes de los defectos inherentes de la consulta, como la Comisión de Venecia, que señaló muy claramente que el referéndum debía llevarse a cabo de conformidad con el ordenamiento constitucional español. A pesar de todas estas advertencias, iban a tomar los caminos salvajes de la independencia que despertarían la reacción del pueblo así como del Gobierno español. Respecto a este último, debemos decir, más vale tarde que nunca, aunque muchas cosas ya estaban podrido debido a una reacción tan tardía.

33 En este sentido, ver: «Los límites de vía canadiense», El País, 20 de septiembre de 2017. 


\subsection{Las reacciones a los referendos}

El desarrollo del referéndum y algunas críticas de los medios, así como las de algunos grupos políticos europeos, provocarían serias reacciones de la población española, que se producirían casi de forma inmediata. De hecho, los españoles comprendieron que este era el momento de actuar para hacer frente como es debido al desafío separatista, lo que provocó al mismo tiempo algún tipo de respuesta de las instituciones, incluida la de la Corona. Así, dos días después del referéndum, el rey Felipe VI denunció en un claro discurso la deslealtad de los líderes separatistas, un discurso que el pueblo español esperaba con impaciencia, porque era consciente de que el gobierno de Rajoy no había estado, ni estaba todavía a la altura de las circunstancias, opinión que apoyamos y que es en gran medida la principal causa de la crisis catalana. Según varias fuentes, sabemos que el 3 de octubre, el Rey había estado por la mañana con la Ministra de Defensa, María Dolores de Cospedal, que previamente había visitado militares de alto rango, y fue justo después cuando se anunció que el Rey daría un discurso a las 15 horas, discurso que tuvo la mayor audiencia en muchos años ${ }^{34}$.

En nuestra opinión, el discurso fue claro y duro, mostrando especialmente que el Estado español tiene el deber de defender el orden constitucional por todos los medios que le da la Constitución. Ningún miembro del Gobierno español había hablado con la claridad del Rey, y el pueblo español empezó a ver algo de luz en el largo túnel catalán, debido principalmente a los sueños de unos pocos iluminados separatistas y a la falta de liderazgo y de acción de muchos políticos a nivel nacional, sobre todo del Gobierno de Madrid. Otro aspecto que debe ser mencionado, y que es muy importante, es que justo después del referéndum, muchas empresas, especialmente las más características de Cataluña, como los bancos La Caixa y el Sabadell, se iban a ir de la región para establecer su sede social e incluso fiscal en otras regiones españolas. Las razones que dieron es fácil de entender, destacando especialmente no solo los riesgos que suponen para estas empresas los líderes separatistas, sino también estar fuera de la zona euro en caso de una posible independencia, este último aspecto actualmente más bien utópico que real.

De este modo, más de 3.500 empresas han abandonado la región, y los efectos se sintieron inmediatamente, como lo demuestra no solo la tasa de

34 Ver «discurso completo del Rey sobre Cataluña», en: https//elpais.com/política/2017/10/03/ actualidad/1507058161_929296.html [consultado: 12/08/2018]. 
desempleo y el crecimiento, sino también y sobre todo, una fuerte paralización de la inversión en la región catalana. Es decir, el mundo económico catalán no quiere estas aventuras, y entre los separatistas hay una gran cantidad de líderes que no comparten la ideología económica liberal o la globalización. También se puede añadir que muchos de los que votan a los separatistas, ni siquiera comparten los valores europeos. Basta con escuchar a Puigdemont para darse cuenta de ello, como cuando tuvo la idea mágica de proponer un referéndum en Cataluña para decidir si se queda en la UE o no ${ }^{35}$. Después de la celebración del referéndum del primero de octubre, el ambiente iba a caldearse en Cataluña, ya que el Gobierno Central empezó a darse cuenta, más por la presión popular que por convicción, del alcance del problema a nivel nacional e internacional.

Hay que decir que algunos países europeos reaccionaron de una manera extraña frente a las cargas de la policía sin saber muy bien los detalles, y sin darse cuenta de que estaban actuando cumpliendo órdenes del poder judicial con el fin de respetar el orden constitucional, debido a que el referéndum era ilegal. Poco a poco las cosas empezaron a estar controladas tanto por el Gobierno español como por el poder judicial. Así la juez Carmen Lamela, de la Audiencia Nacional, envía a prisión el 6 de octubre a Jordi Sánchez y a Jordi Couixart, que presidían la Asamblea Nacional Catalana y Ómnium Cultural, respectivamente, por varios delitos violentos que cometieron el 20 de septiembre, siendo acusados de sedición. Ambos continúan en prisión. Otro aspecto que se debe señalar es la movilización general de los anti-separatistas en toda la región. Tanto es así que el 8 de octubre tuvo lugar una gran manifestación en Barcelona, en la que alrededor de un millón de personas salen a las calles con banderas españolas defendiendo la unidad del Estado español ${ }^{36}$.

Esta es la primera vez que los anti-separatistas muestran abiertamente su clara oposición a las tesis independentistas, mientras que los separatistas empiezan a darse cuenta de que no son los únicos que viven en Cataluña, y la idea que han diseminado de que todo el pueblo catalán quiere la independencia no sólo es falsa, sino también un gran error político. Han sembrado el odio en la sociedad catalana e ignorado y despreciado la capacidad de respuesta de

35 Véase, La Vanguardia (Barcelona) de 26 de noviembre de 2017. En la declaración hecha en el canal de la televisión pública israelí 1 Khan, muestra su desencanto con las instituciones europeas frente al tema catalán.

36 Entre estos manifestantes también hay gente de toda España que ha venido para apoyar la unidad nacional. 
los españoles, errores que están pagando caro, tanto a nivel económico como político y social. El resultado es una sociedad rota y dividida, donde todo el mundo es sospechoso de los otros que no comparten la misma opinión, y de donde las empresas huyeron por la inseguridad generada. Por el momento, las declaraciones de algunos ministros del Gobierno español en la que se invita a las empresas a volver tan pronto como sea posible, no tuvieron efecto, y han atraído gran rechazo de los españoles.

Al mismo tiempo, los bancos han comenzado a desmontar el mito internacional de «España nos roba $»^{37}$ una cosa que, como ya hemos mencionado, demuestra que Cataluña no es en la actualidad lo que los separatistas están predicando, es decir, que no son los únicos que contribuyen al presupuesto del Estado.

\subsubsection{La Declaración de Independencia del 10 de octubre}

En la confusión generada con el referéndum del primero de octubre, el ya ex presidente catalán Puigdemont añadiría una tragicomedia más a su «show» cuando el 10 de octubre de 2017, poco después de las 19 horas, dijo lo siguiente en el Parlamento catalán: «Asumo... el mandato del pueblo de que Cataluña se convierta en un Estado independiente en la forma de una República... y con la misma solemnidad, el gobierno y yo mismo proponemos que el Parlamento suspenda los efectos de la declaración para que en las próximas semanas emprendamos un diálogo sin el cual no es posible llegar a una solución acordada ${ }^{38}$.

Es decir, con esta declaración el presidente Puigdemont validó los resultados del referéndum del 1 de octubre, que se llevó a cabo sin garantías y con una gran cantidad de irregularidades, además de estar prohibido por la justicia española. Pero no solo eso, sino que además también violó la propia ley sobre el referéndum catalán, que incluía la declaración de independencia 48 horas después de declarar los resultados de la consulta, y, sin embargo, estos se dieron a conocer oficialmente el 6 de octubre. Todo este caos demuestra una locura evidente que prevalecía en las cabezas de los líderes separatistas ${ }^{39}$.

37 En este sentido, véase la «banca internacional comienza a desmontar el mito del robo a Cataluña (con números)», en https://www.infobolsa.es/news/detail?key=201710163797795source= EI_ULTIMAS [consultado: 13/08/2018].

38 Véase El País, 11 de octubre, 2017.

39 Para mucho más detalles sobre este período y sobre el procés en general, véase MARCH LEDESMA, O., Los entresijos del «procés», Catarata, 224 p. 
Pero el teatro no terminó ahí, porque inmediatamente después de su discurso Puigdemont firmó con el resto de diputados independentistas una declaración de independencia en la que se dice claramente que «nosotros constituimos la República catalana como un Estado independiente y soberano, de derecho, democrático y social... disponemos la entrada en vigor de la ley sobre la transitoriedad jurídica y constitutiva de la República...

Estamos lanzando el proceso constituyente, democrático, contando con la ciudadanía, transversal, participativo y con efecto vinculante ${ }^{40}$. Esta declaración se refiere también a otras cuestiones, como a la operación policial del 1 de octubre, calificada como contraria a las libertades de los ciudadanos catalanes y a los derechos humanos. Se señala también que el pueblo catalán es respetuoso del estado de derecho, y que la declaración responde a que el Estado español les ha impedido ejercer el derecho a la autodeterminación... etc. La confusión generada por la declaración de Puigdemont del 10 de octubre suscitaría una respuesta política muy débil por parte del Gobierno español, ya que a pesar de que la declaración estaba llena de contradicciones, un hecho tan grave que nunca se ha producido en España en el período posterior a Franco, hubiera de ser detenido inmediatamente por sedición, ya que constituye el caso tipo previsto en el código penal español.

De hecho, está claro que declaró la independencia, aunque de manera solapada y manipuladora, invocando el diálogo y la concordia como una especie de coartada, con el objetivo de abrir un proceso constituyente para crear la república catalana. Pero a pesar de esta declaración de independencia, en nuestra opinión el Jefe del Gobierno español envió una notificación oficial al presidente catalán el 11 de octubre de 2017, indicando además un plazo determinado, fijado para el 16 de octubre, durante el cual estaba obligado a dar una respuesta antes de este día. Al mismo tiempo, el jefe del Gobierno español dio el primer paso para iniciar el procedimiento previo antes de aplicar el ya famoso artículo 155 de la Constitución, advirtiendo al presidente catalán de sus consecuencias ${ }^{41}$.

40 Ibidem.

41 El contenido de la notificación alude al acuerdo del Consejo de Ministros del 11 de octubre, en el que se advierte al presidente catalán de que lo que está haciendo con sus decisiones es completamente contrario al interés general de España: «En cumplimiento del Acuerdo adoptado por el Consejo de Ministros en la Reunión celebrada el día 11 de octubre de 2017, me dirijo MH para dar traslado, mediante la adjunta certificación, de la decisión del Gobierno relativa al requerimiento, en aplicación de lo dispuesto en el artículo 155 de la Constitución, para que proceda al cumplimiento de sus obligaciones constitucionales, y legales y a la cesación de sus actuaciones gravemente contrarias al interés general de España». Ver, portada de El País, del 12 de octubre de 2017. 
Como la respuesta no se hizo antes de esa fecha, lo que no sólo es una clara desobediencia al Gobierno español, sino también un desprecio imperdonable contra el Estado, el Jefe del Gobierno, Mariano Rajoy, le envió una carta oficia$1^{42}$ en la que se queja no sólo de la falta de respuesta, sino que incluso le reprocha no haber aclarado la cuestión de si alguna autoridad del Gobierno de Cataluña declaró la independencia de la región. Pero Mariano Rajoy, en vez de cortar con este tira y afloja, y continuar con el procedimiento previsto en el artículo 155 de la Constitución, le da un nuevo período de tres días, es decir hasta el 19 de octubre a 10 horas.

La pusilanimidad del Gobierno de Rajoy es, pues, absoluta, y poco diligente, dadas las graves circunstancias, al menos esto es lo que da a entender. En este contexto, el mismo día de 16 de octubre, el presidente Puigdemont respondió diciendo que la situación actual de Cataluña es tan trascendente que exige respuestas y soluciones políticas que estén a la altura de las circunstancias, y que hay que encontrar soluciones a través del diálogo, la negociación y el acuerdo. Además, el presidente catalán hizo al Presidente español Rajoy dos peticiones para resolver la cuestión catalana: La primera se refiere a la represión que sufre no sólo el pueblo catalán, sino también el gobierno catalán, represión que debe cesar de inmediato; la segunda se refiere a la necesidad de llegar a un acuerdo tan pronto como sea posible para reunirse y explorar los primeros acuerdos, asegurando, dijo el Presidente catalán, de que podrán llegar a una solución ${ }^{43}$. En esta tensa situación, las posibilidades de llegar a una colaboración o a establecer un diálogo entre el Gobierno de Madrid y el catalán es extremadamente difícil, mientras que los tribunales españoles estaban esperando ansiosamente el curso de la crisis.

Sin embargo, la negativa de Carles Puigdemont a añadir un poco de luz sobre la cuestión de si había hecho o no una Declaración de independencia, puso en alerta al sistema judicial español, que comienza a poner en marcha el derecho penal y, ordena prestar declaración a los primeros acusados de sedición, a saber, el jefe de la policía catalana Josep Lluís Trapero, y los presidentes de las asociaciones de la independencia Asamblea nacional catalana $(\mathrm{ACN})$ y Ómnium Cultural, Jordi Sánchez y Jordi Cuixart, respectivamente,

42 Ver el texto en: http://www.lamoncloa.gob.es/consejodeministros/resumenes/Páginas/2017/11 1017 consejoministros.aspx [consultado: 13/08/2018].

43 Para el texto de esta carta, véase La Vanguardia, del 16 de octubre de 2017. En este artículo, también está la carta de Rajoy. Como se puede comprobar vuelve a insistir sobre el carácter represor del Estado español sin tapujos. 
estos dos últimos aún en prisión, ${ }^{44}$. En estas circunstancias, la suspensión de la autonomía catalana también avanzó a pasos agigantados, y produjo reales pesadillas a las autoridades regionales, especialmente al presidente Puigdemont. Él sabía que la era de la ambigüedad infinita estaba llegando a su fin, ya que el artículo 155 estaba casi ahí. Por otro lado, la perifrástica de la declaración de independencia del 10 de octubre, llegaba a su fin, y Puigdemont era consciente de las consecuencias que podrían ocurrir si el Gobierno de Madrid aplicaba el citado artículo 155. Pero incluso si el tiempo se acortara, Puigdemont aún tenía una última oportunidad para no aplicar esta disposición: Convocar elecciones, y este simple hecho podía hacer que todo volviera a la situación de legalidad.

Esta es la razón por la que convocó a los líderes de los partidos independentistas para debatir qué hacer, pero había una gran variedad de opiniones sobre este tema. Mientras que algunos defendieron la idea de continuar so pena de ser considerados como traidores, otros eran mucho más flexibles. Incluso el presidente del País Vasco, Urkullu, le había llamado por teléfono tres veces el 24 de octubre para decirle que lo más importante era la convocatoria de elecciones y preservar las instituciones catalanas. Esta opinión también fue compartida, aunque «en voz baja», tanto por la Comisión Europea como por el Vaticano ${ }^{45}$. En cuanto al Vaticano, sabemos que el actual Papa no comparte las tesis separatistas, ya que en muchas ocasiones ha afirmado que el derecho a la autodeterminación es sólo para los pueblos coloniales. Además, no le gusta la falta de solidaridad de los independentistas catalanes con algunas regiones más pobres españolas ${ }^{46}$.

En cuanto a la Comisión Europea, ha repetido una y mil veces que la crisis catalana era un asunto interno español y, como el Vaticano, siempre se negó a jugar el papel de mediador en esta crisis. Dicho esto, una cosa parece clara en este revoltijo de detalles: Puigdemont estaba a favor de convocar elecciones, pero algunos separatistas radicales lo condujeron por el camino equivocado, conociendo bien su débil personalidad.

44 Para más detalles, véase «La justicia en 'stand by' a la espera de Puigdemont» El Periódico, 14 de octubre de 2017.

45 Para más detalles, sobre estos temas, véase «Los tres días que conmocionaron Cataluña», El País (digital), https://politica.elpais.com/politica/2017/11/25/actualidad/1511634052_767273.html [consultado: 10/08/2018].

46 Para más detalles sobre el papel de la Iglesia en la crisis catalana, ver «La Iglesia y el proceso soberanista (post artículo 155)», El País, del 19 de diciembre de 2017. 


\subsubsection{El Senado aprueba la aplicación del artículo 155 de la} Constitución

En este contexto llegamos al 27 de octubre, un día en que se produjeron dos hechos importantes: Por un lado, el Parlamento catalán aprueba, poco después de las 15 horas, una resolución en la que se proclamó unilateralmente la independencia de Cataluña por 70 votos a favor, 10 en contra y dos votos en blanco, mientras que los diputados constitucionalistas no participaron en la votación, abandonando la sala del Parlamento ${ }^{47}$; y una hora más tarde, el Senado español autoriza la aplicación del artículo 155 de la Constitución, que permite al Gobierno español intervenir la Comunidad Autónoma catalana y cesar a los miembros del ejecutivo catalán, algo que iba a suceder de forma casi automática, ya que en esa misma noche, el presidente del Gobierno español, Mariano Rajoy, anunció la disolución del parlamento catalán y la celebración de elecciones para el 21 de diciembre.

Al día siguiente, se destituye al Presidente Puigdemont y a los Consejeros de su gobierno, mientras que el Ministro del Interior destituía de sus funciones a los principales líderes de los Mossos d'Esquadra, es decir, la policía regional catalana. Por su parte, Mariano Rajoy delegaba todas las competencias de la Generalitat, el gobierno catalán, en la Vicepresidenta del Gobierno español, Soraya Sáenz de Santamaría. Así que todo se realizó de forma rápida y sin dudar, lo que demuestra que todo estaba ya bien preparado tras las muchas, más que muchas, demasiadas oportunidades que se habían ofrecido al Presidente catalán para que corrigiera el tiro y volviera al camino de la legalidad.

Que el artículo 155 funcionó relativamente bien, no cabe la menor duda, a pesar de que en nuestra opinión se tenía que haber aplicado antes. Y si no se aplicó antes se debe a la oposición en su momento del Partido socialista, frente a la de Ciudadanos, que lo venía reivindicando desde hacía ya algún tiempo. Evidentemente la aplicación del artículo 155 sería considerada por el Gobierno catalán y los líderes independentistas como un golpe de Estado. Sin embargo muchas voces se han alzado por haber dejado fuera de su alcance de acción la Cadena de televisión TV3, que sistemáticamente ha sido una máquina de desinformación relevante, elaborando programas muy pocos respetuosos con las instituciones del Estado y con el pueblo español en general, dejando caer

47 Sobre esta cuestión, ver infra (nota). 
mensajes poco acordes con la realidad, sobre todo en relación con la educación en las escuelas y con las fuerzas de seguridad del Estado. Es más, en algunos casos era obvio que se atisbaba incluso en sus programas mensajes más o menos ocultos de odio hacia el pueblo español, que han sido constantes por cierto en muchos discursos de los líderes independentistas. Somos conscientes de las dificultades que su intervención hubiera supuesto para libertades tan básicas como la libertad de expresión, pero una vez que se vio claramente que no se corregía el tiro, habría que haberla intervenido, al menos temporalmente, para hacerla ver que el Estado de Derecho no podía tolerar impunemente esa clase de acciones.

Y en relación con los Mossos d'Esquadra, la intervención hubiera debido ir mucho más lejos, como la opinión pública lo ha puesto de manifiesto en numerosas ocasiones, pues su comportamiento durante la jornada del 1-O es indigna de una fuerza de seguridad del Estado, que es en realidad de lo que se trata. Es más, se hubiera tenido que articular mecanismos para saber quiénes eran realmente aquellos que estaban al servicio de una presunta República catalana (en torno a un 55 por ciento) y quiénes no (se ha dicho y repetido que en torno a un 45 por ciento). No hay que olvidar que en esta policía se integraron bastantes miembros de la guardia civil y de la policía nacional presentes sobre todo en la zona. Estas medidas hubieran regenerado la confianza en esta policía con la que el pueblo español no tiene ninguna confianza. Y los hechos cometidos por varios mandos de esta policía, hechos que están siendo investigados, así lo corroboran.

\subsection{La Declaración de Independencia del 27 de octubre 2017 ¿Real o simbólica?}

La resolución del Parlamento catalán del 27 de octubre en la que se proclama la independencia sigue las líneas de la proclamada anteriormente, diciendo que se constituye la República catalana como Estado independiente y soberano de derecho, democrático y social. Sin embargo, a pesar de estas palabras tan rimbombantes, no se ha hecho una verdadera Declaración de independencia, sino más bien una lista de medidas para hacer más efectiva la ley de transición jurídica. Desde esta perspectiva, hay que recalcar que la resolución en cuestión no fue publicada en el Boletín Oficial del Parlamento catalán, ni tampoco en el Diario Oficial de la Comunidad Autónoma. Incluso la prensa internacional, aunque también la nacional, señalaron 
inmediatamente que era más bien una declaración más formal y simbólica que real ${ }^{48}$. Esta interpretación también se deduce del comportamiento de las autoridades catalanas, porque asumen la aplicación del artículo 155 de la Constitución, en general, sin resistencia. Pero dicho esto, lo que está claro es que los líderes separatistas trataron de ver qué reacción provocaría tal Declaración, tanto a nivel nacional como a nivel internacional, y aquí es donde se equivocaron.

Pero dicho esto, conviene poner de relieve que esta clase de declaraciones de independencia son la consecuencia de una seria de hechos más o menos violentos o revolucionarios que jurídicamente hablando desde un punto de vista constitucional son nulas, poco importa donde se lleven a cabo. No obstante, es evidente que si esa declaración se hace en el máximo órgano legislativo autonómico, como es el Parlamento de Cataluña, el desafío jurídico al orden constitucional es mayor que si se hubiera hecho, por ejemplo, en la Barceloneta, pero no por eso la dota de un mayor alcance jurídico. Cuestión distinta es si se analiza este tema desde un punto de vista político, como se ha podido comprobar ulteriormente, tanto a nivel político como judicial.

Llegados a este lugar, conviene plantearse la cuestión de saber cómo aborda el Derecho internacional la cuestión de las declaraciones de independencia, dejando ahora al margen la cuestión de su efectividad, que abordamos infra. Lo primero que conviene recalcar es que, en todo caso, el Derecho internacional ha sido siempre reacio a la independencia de los pueblos, casi podría decirse que ha venido manifestando «una tendencia... natural» ${ }^{49}$, propia de un Ordenamiento jurídico creado por Estados soberanos, contra las ambiciones secesionistas de los nacionalismos. Un mundo de dos mil Estados-nación no sería, seguramente, un buen lugar para vivir, porque ni sería particularmente pacífico, y por tanto gobernable, ni progresaría como lo hemos hecho durante el pasado medio siglo hacia la democracia y el respeto de los derechos humanos. Es más, como la democracia tiende a florecer en la diversidad, que requiere mutuo respeto y acomodación de los diversos intereses, la disolución de los Estados plurinacionales en sus diversas unidades dificultaría alcanzar este

48 En este sentido, véase, Le Monde, del 28 de octubre: «Catalogne: les indépendantistes proclament une république symbolique», http://www.lemonde. Pero también en España los periódicos estaban trabajando en este tema de la misma manera.

49 FRANCK, Th.M., «Personal self-determination: The next wave in constructing identity», Legal visions of the 21st. century: Essays in honour of judge Chistopher Weeramantry, A. Anghi y S. Sturgess (ed.), La Haya-Londres-Boston, Kluwer Law International, 1998, p. 256. 
necesario equilibrio. Esta reflexión de Franck ${ }^{50}$ recuerda enormemente en el fondo a la propuesta hecha por Carlos Westendorp en relación con Kosovo ${ }^{51}$ cuando consideraba que es preciso apostar, a pesar de todo, por la autonomía y no por la independencia, y ello a fin de evitar cuidadosamente que se repita en Kosovo la división en entidades políticas «étnicas», que sería como dar la razón a Milosevic, consagrando una separación entre serbios y albaneses como si no pudieran convivir nunca más en un mismo territorio.

Sin embargo, si esta tendencia es evidente, esto no quiere decir forzosamente que una declaración de independencia sea ilegal según el Derecho internacional, pues todo dependerá de cómo esta se ha llevado a cabo. Esta es la opinión al menos de la Corte Internacional de Justicia en su dictamen del 22 de julio de 2010 en el asunto sobre Kosovo. Como se sabe, fue a iniciativa serbia que la Asamblea General adopta la resolución 63/3 del 8 de octubre de 2008, pensando en una aclaración jurídica de los problemas planteados por la Declaración de independencia de Kosovo de 17 de febrero de 2008. El interés suscitado por la solicitud a la Corte fue in crescendo, como lo demuestra el hecho de que nada menos que 35 Estados depositaran sus escritos para defender sus tesis ante aquella, entre los que se encuentra España, pero también, por ejemplo, las Maldivas, Sierra Leona o Bolivia..., sin olvidar a los cinco miembros permanentes del Consejo de Seguridad ${ }^{52}$.

Esta cuestión está clara para la Corte, ya que después de afirmar que las declaraciones de independencia fueron numerosas en los siglos XVIII, XIX y a principios del XX, suscitando una fuerte oposición de los Estados en los que se llevaban a cabo, concluye sin embargo afirmando que «no se deduce en general de esta práctica que la declaración de independencia haya sido alguna vez considerada como una violación del Derecho internacional ${ }^{53}$. Por otro lado, la Corte reconoce que en la segunda mitad del siglo XX, el Derecho internacional ha evolucionado hacia el reconocimiento de un derecho a la independencia basado en el derecho de autodeterminación de los pueblos coloniales, así como de aquellos sometidos a la dominación o a la explotación extranjeras, de

\footnotetext{
50 Ibid, p. 255.

51 Kosovo. «Las lecciones de Bosnia», Política Exterior, XIII, julio-agosto 1999, nº70, p. 45.

52 El texto, que hace fe, raza así: «Is the unilateral declaration of Independence by the provisional Institutions of Self-Government of Kosovo in accordance with international Law? Ver párrafo 1 de la Opinión consultiva de 22 de julio de 2010 en el asunto sobre la conformidad de la declaración unilateral de independencia relativa a Kosovo (http://www.icj-cij.org).

53 Ver párr. 79.
} 
forma que muchos Estados han nacido al ejercer este derecho. Pero al mismo tiempo señala que durante este período también ha habido declaraciones de independencia al margen de ese derecho de autodeterminación, insistiendo la Corte en sus tesis al afirmar:

«La práctica estatal en estos casos no apunta a la aparición en el Derecho internacional de una nueva regla que prohíba efectuar una declaración de independencia».

Evidentemente, estas afirmaciones de la Corte son preocupantes, ya que según sus tesis cualquier entidad infraestatal podría declarar su independencia, generando no sólo inseguridad sino, lo que es más grave, eventuales conflictos en los Estados y, llegado el caso, entre los Estados. Es comprensible por ello que varios Estados participantes en el procedimiento ante la Corte hayan afirmado que esa prohibición se deduce implícitamente del principio de integración territorial ${ }^{54}$. Pero la Corte rechaza esta tesis con una argumentación que nos parece inaceptable como intentamos demostrar más adelante.

La Corte va incluso más lejos en sus argumentos al rechazar también la tesis de que las decisiones del Consejo de Seguridad condenando algunas declaraciones de independencia, como la de Rodesia del Sur, la de Chipre del Norte o la más reciente de la República de Srpska, puedan alegarse como una práctica (condenatoria, claro) aplicable a la Declaración unilateral de independencia de Kosovo. Y es que, para el Tribunal,

«La ilicitud de estas declaraciones procedía no de su carácter unilateral, sino porque iban acompañadas o se habían llevado a cabo mediante un recurso ilícito al uso de la fuerza o mediante violaciones graves de normas de Derecho internacional general, particularmente de naturaleza imperativa (ius cogens)».

La interpretación que hizo la Corte en torno a esta cuestión no gustaría a algunos jueces, como Simma y Cançado Trindade. Sin embargo, al amparo de la Resolución 1244 del Consejo de Seguridad, este órgano de las Naciones Unidas había creado una administración provisional de Kosovo con pleno respeto de la integridad territorial yugoslava hasta alcanzar un estatuto definitivo

54 Ver párrafo 80 in fine. 
para ese territorio que el Consejo debería aprobar, lo que nunca haría. Esta línea argumental de la Corte sería rebatida de forma contundente por el juez Skotnikov en los siguientes términos:

«There is also a problem with the Court's interpretation of general international law. According to the Advisory Opinion, 'general international law contains no applicable prohibition of declarations of independence' (paragraph 84). This is a misleading statement which, unfortunately, may have an inflammatory effect. General international law simply does not address the issuance of declarations of independence, because 'declarations of independence do not create or constitute States under international law. It is not he issuance of such declarations that satisfies the factual requirements, under international law, for statehood or recognition. Under international law, such declarations do not constitute the legal basis for statehood or recognition [CR 2009/31, p. 46 (Fife, Norway)]... Therefore, the question as to the legality of the UDI simply cannot be answered from the point of view of general international law. The only law applicable for the purpose of answering the question posed by the General Assembly is the lex specialis created by Security Council resolution 1244 ${ }^{55}$.

Pero la Corte en relación con esta idea lanza después otro argumento también peligroso en relación con el principio de la integridad territorial del Estado, al señalar que «el alcance del principio de integridad territorial» (del que al menos reconoce que es «un elemento importante del Ordenamiento jurídico internacional») «se limita a la esfera de las relaciones interestatales ${ }^{56}$. Es decir, lo que deja claro la Corte es que estos asuntos deben resolverse como sea en el marco interno del Estado en cuestión que es el que tiene que defender esa integridad territorial. Evidentemente, esta afirmación no solo es simplista y de un formalismo feroz, a la que se opusieron no solo el juez Skotnikov, ya mencionado, sino también el juez Bennouna ${ }^{57}$, así como el Vicepresidente Tomka $^{58}$ y el juez Yusuf ${ }^{59}$.

Esto explica en gran medida el regocijo de los líderes independentistas catalanes, y también en parte vascos, que pronto señalaron que ese era el ca-

55 Ver párrafo 17 de su Opinión disidente.

56 Ver párr. 80.

57 Ver párrafo 30 de su Opinión disidente.

58 Ver su declaración, párrafo 10.

59 Ver párrafo 6 de su Opinión individual. 
mino a seguir, y en gran medida los líderes catalanes lo han hecho. Basta con llevar a cabo un somero análisis cronológico de la situación para apercibirlo, aunque evidentemente los elementos de fondo fácticos sean completamente distintos.

Desde esta perspectiva, hay que reconocer que a nivel nacional, España ha reaccionado muy tarde, y lo hizo con las armas que le había dado la Constitución, entre otras disposiciones, el artículo 155, a pesar de que debería haber reaccionado mucho antes a todos los niveles, legales y políticos al contar además con el amparo del Derecho internacional, como ya hemos apuntado ${ }^{60}$. Cuando el Gobierno español comenzó a responder, la situación ya estaba muy deteriorada, y de una crisis estrictamente nacional e interna, se fue a una crisis más o menos internacional. Sin embargo, a nivel internacional ningún Estado digno de este nombre ha reconocido a Cataluña, ya que como ha señalado de una manera muy clara el Profesor Marcelo Cohen, «pour le droit international il ne s'est rien passé vendredi ( 27 octobre) à Barcelone» ${ }^{61}$. Llegados a este punto, cabría preguntarse qué hubiera ocurrido si algunos Estados hubieran reconocido a la República catalana tras estas declaraciones de independencia, sobre todo la del 27 de octubre de 2017. Pues bien, ello hubiera supuesto una clara violación del principio de no intervención en los asuntos internos del Estado español, ya que, como se ha apuntado por la doctrina, cuando un pueblo, que forma parte de un Estado, proclama sin justificación jurídica alguna unilateralmente su independencia, esos reconocimientos de terceros Estados

60 Podría haberse invocado también el artículo 116, o incluso leyes como la de Seguridad Nacional. Sin embargo, el artículo 155, artículo que está inspirado en el artículo 37 de la Ley Fundamental de la entonces República Federal de Alemania de 22 de mayo de 1949 (aprobada el 8 de mayo de 1949 y promulgada el 22) así como en el artículo 126 de la Constitución italiana. Sin embargo, hay que reconocer que la aplicación del artículo 155 era el más adecuado para la situación generada en Cataluña, que ha ido evolucionando por unos derroteros completamente irracionales. Además, ya había partidos, como Ciudadanos, que venían reivindicando su aplicación desde hacia ya mucho tiempo.

${ }^{61}$ En este sentido, el profesor Marcelo Cohen dijo lo siguiente: «Pour le droit international, il ne s'est rien passé vendredi à Barcelone. Le droit international ne reconnaît pas à la Catalogne un droit de devenir indépendant. Le gouvernement catalan sait très bien qu'aucun Etat ne va reconnaître l'indépendance de la Catalogne et qu'il ne pourra pas adhérer à l'ONU ou à l'Union européenne. D'où l'ambiguïté dans la résolution du parlement catalan. Le texte parle plutôt du début d'un processus d'indépendance. A titre de comparaison, dès le lendemain de la proclamation du parlement kosovar en février 2008, plusieurs pays, dont la Suisse mais pas l'Espagne, avaient reconnu le Kosovo. Pour la Catalogne, ce ne sera pas le cas. J'en suis persuadé». Ver: https://www. letemps.ch/monde/2017/10/27/marcelo-kohen-droit-international-ne-sest-rien-passe-barcelone [consultado: 12/08/2018]. 
constituyen una interferencia claramente ilegal ${ }^{62}$. Es, pues, a nivel internacional, donde los separatistas han perdido sobre todo la batalla, no sólo porque sus puntos de vista son contrarios al Derecho internacional, sino porque la comunidad internacional, y en especial algunos países europeos y latinoamericanos, han apoyado firmemente la unidad española, algo que se tendrá que agradecer con gran generosidad si el Gobierno español quiere hacer en esta crisis algo bueno, incluyendo el Reino Unido.

Por otra parte, a pesar de que los líderes separatistas han dado el ejemplo de Kosovo como un camino a seguir, también están engañados porque los dos casos no son comparables. En primer lugar, porque los Estados que han reconocido la independencia de Kosovo dijeron que era una «excepción», recurriendo así al argumento del Enviado especial de las Naciones Unidas, el finlandés Martti Ahtisaari, es decir, el que aprobó el plan para Kosovo, señalando que era un caso único, aunque a pesar de ello, el plan fue un grave error que Europa todavía está pagando las consecuencias ${ }^{63}$. Cabe señalar a este respecto que España no lo ha reconocido. En segundo lugar, está claro que el caso catalán no es el de Kosovo, ni España un país balcánico de una guerra como la de la antigua Yugoslavia.

Ya sabemos que los líderes independentistas han logrado inculcar en las mentes de una cierta opinión pública de la región catalana la idea de que España no es un Estado democrático, sino fascista, utilizando para ello una buena comunicación con los medios, sobre todo extranjeros, algo que no ha sabido hacer el Gobierno Central. No obstante, esta tendencia a los independentistas no ha calado muy profundamente fuera de nuestras fronteras, salvo en casos muy aislados, como pueda ser Bélgica, por los flamencos, Eslovenia y Estonia. $\mathrm{Y}$ es que considerar a España como un país no democrático y represor, cuando está entre los veinte primeros en las estadísticas internacionales como

62 A este respecto, véase, por ejemplo, entre otros muchos, los comementarios que sobre esta cuestión lleva a cabo SALMón, J.J.A., La reconnaissance d'Etat: Quatre cas: Mandchoukuo, Katanga, Biafra, Rhodésie du Sud, París, Armand Colin, 1971, pp. 36 y ss.; y SEN, B., A diplomat's handbook of International Law and practice, Dordrecht, M. Nijhoff, 1988 ( $3^{\mathrm{a}}$ ed. revisada), pp. 510-511.

63 En el caso de Kosovo, hemos publicado varios estudios en colaboración con el profesor Cesáreo Gutiérrez Espada de la Universidad de Murcia. Véase, por ejemplo, La disolución de Yugoslavia, Pamplona, Eunsa, 2007, 270 p. ; y Gutiérrez EsPada, C.; Bermejo García, R., De la Opinión consultiva de la CIF, de 22 de julio de 2010, sobre Kosovo, Doc. De Trabajo 35/2010, 10/11/2010, pp. 1-13 [http://www.realinstitutoelcano.org]; BERMEJO GARCÍA, R.; GuTiÉrREZ EsPADA, C., «La declaración unilateral de independencia de Kosovo a la luz de la Opinión Consultiva de la CIJ, de 22 de julio de 2010 y de las declaraciones, opiniones individuales y disidentes a la misma», Anuario Español de Derecho Internacional, 26, 2010, pp. 7-59. 
Estado con mayores dosis democráticas, es completamente irracional ${ }^{64}$. Por eso, las comparaciones que se han hecho con Kosovo no solo es un insulto a la historia, sino que solo cabe en mentes llenas de odio hacia aquellos que no comporten sus planteamientos.

En efecto, como se sabe, el conflicto en la antigua ex Yugoslavia ha sido el más complejo y cruel en Europa desde la Segunda Guerra Mundial, en donde tuvieron lugar graves y sistemáticas violaciones de los derechos humanos, siendo Kosovo precisamente uno de los peores escenarios. Aunque el tema de los derechos humanos en Kosovo se remonta a antes de que se desencadenara el conflicto en la zona, pues las autoridades de Belgrado empezaron a adoptar determinadas medidas restrictivas frente a su pueblo ya en la década de los ochenta, todavía cuando el conflicto en la antigua ex Yugoslavia parecía llegar a su término al haberse adoptado los Acuerdos de Dayton en diciembre de 1995, Kosovo seguía estando sobre el tapete de actualidad internacional y las violaciones de los derechos humanos, con cientos de miles de refugiados, también. De esta situación se ocuparon todos los órganos de las Naciones Unidas, cada uno evidentemente dentro de sus propios ámbitos de competencia, como bien pone de manifiesto el Juez Cançado Trindade en su extensa e interesante Opinión individual ${ }^{65}$.

$\mathrm{Y}$ es que el conflicto entre el Ejército de Liberación de Kosovo (LK/ UÇK) con las fuerzas serbias de Belgrado llegó a adquirir tintes, como todos sabemos, dramáticos. Por eso precisamente la OTAN decidió en la primavera de 1999 llevar a cabo los bombardeos sobre lo que quedaba de Yugoslavia por razones humanitarias, y sin autorización expresa del Consejo de Seguridad. $\mathrm{Al}$ margen de la legalidad o no de esta intervención, el Consejo de Seguridad adoptó el 10 de junio de 1999 la Resolución 1244, actuando en el marco del Capítulo VII de la Carta de las Naciones Unidas. Esta, después de reconocer

64 Por ejemplo, España está en el puesto 19, por delante de los Estados Unidos, Francia, Japón, Portugal, Italia y también del Reino de Bélgica, en donde Puigdemont ha encontrado refugio, que está en el puesto 32. Los hechos se pueden tergiversar, pero son los que son. Véase a este respecto la lista de países en: https://es.wikipedia.org/wiki/Indice_de_Democracia\#tlassificacion_ de_2017 [consultado: 08/08/2018].

65 Ver sobre todo, párr. 97 y ss. Sobre esta cuestión Kosovar, véase CIf, Conformité au droit international de la déclaration unilatérale d'indépendance relative au Kosovo, avis consultatif du 22 juillet 2010. A este respecto, ver el estudio de CREPET DAIGREMONT, C., «Conformité au droit international de la déclaration d'indépendance relative au Kosovo», Annuaire français de droit international, 2010, pp. 229-247. Posteriormente, la Opinión Consultiva de la Corte Internacional de Justicia sobre Kosovo continuó estando durante varios años en la preocupación de muchos internacionalistas por razones diversas, algunas de las cuales ya las hemos comentado. 
que el Consejo de Seguridad estaba decidido a remediar la grave situación humanitaria de la zona y a poner fin al conflicto armado en Kosovo, autorizó al Secretario General de las Naciones Unidas a establecer una presencia civil internacional con el fin de instaurar una administración provisional sobre el territorio. También exigía a las autoridades de Belgrado poner fin a la violencia y a la represión en Kosovo, así como a iniciar la retirada de todas las fuerzas militares, paramilitares y de policía según un calendario preciso, y al ALK y otros grupos armados de Kosovo a que pusieran fin a las operaciones militares ofensivas.

Es evidente que nada de esto ha ocurrido en la Comunidad Autónoma de Cataluña, y que España ha ejercido los derechos y obligaciones que le incumben como Estado soberano sobre ese territorio español, siempre en el más estricto respeto del Estado de Derecho y los derechos humanos. Pretender lo contrario es pura y simplemente falsear la realidad.

Desde esta misma perspectiva, no conviene olvidar, además, que, para que una declaración de independencia pueda ser efectiva y real en el Derecho internacional, es necesario un control efectivo y exclusivo en el territorio en cuestión, que no es el caso de Cataluña donde el Estado español siempre ha tenido la soberanía en sus manos. Que el Estado español tuvo el control del territorio en sus manos deja claro el referéndum ilegal del primero de octubre, pese a la traición cometida por varios dirigentes de la policía catalana. Sobre esta cuestión, pocas dudas se suscitan al respecto, pues como se ha recalcado recientemente, invocando las reglas básicas del Derecho internacional, «una declaración de independencia es una expresión de voluntad que ha de ser confirmada por las obras, esto es, por su efectividad. Una declaración de independencia no se mide por el rasero del Derecho, sino por el de sus efectividades en acción, el ejercicio de competencias soberanas, el control del territorio. La efectividad de una declaración de independencia es la premisa sin la cual quien se pretende Estado soberano carece de sustentación ${ }^{66}$.

Lo que sucedió en Cataluña ese día, es completamente diferente del caso de Eslovenia, en la antigua Yugoslavia, donde la policía eslovena obtuvo inmediatamente el control territorial de la República después de lo que se llamó «la guerra de los diez días, una guerra asimétrica dirigida contra las fuerzas de Belgrado ${ }^{67}$.

66 Remiro Brotons, A.; Andrés Sáenz de Santamaría, P., «Cuestión catalana», op. cit., p. 292.

67 Para un somero análisis de esta Guerra, ver SvajneER Brigadier JanEZ, J., «War for Slovenia», Slovenska vojska (Revista del Ministerio de Defensa esloveno), mayo 2001. Este autor señala que la guerra se ganó con ciudadanos armados y por las fuerzas de policía eslovenas. 
Nada de esto ocurrió en Cataluña, y estos hechos son esenciales para el Derecho internacional, que se basa precisamente en el principio de efectividad. Dicho esto, es evidente que la crisis catalana debe resolverse a nivel interno español y en el marco legal y constitucional nacional. Y la respuesta es clara a nivel jurídico, debido a que los catalanes no tienen derecho a la autodeterminación. El resultado de toda esta historia sobre la crisis catalana es que, como todo el mundo sabe, el ya ex presidente Puigdemont abandonó a su pueblo catalán al huir a Bélgica, donde ha estado a gusto junto con otros independentistas más o menos, pero que no son particularmente catalanes, sino flamencos.

\section{LA CRISIS CATALANA Y LA COOPERACIÓN JUDICIAL EUROPEA: ¿ORDEN O DESORDEN?}

Como es sabido, el exPresidente catalán Puigdemont no tuvo el valor para sentarse delante de los jueces españoles, como lo hicieron otros líderes separatistas, lo que revela una prueba más de la naturaleza despreciable y falta de principios morales de este personaje, que es capaz de dejar a su propio pueblo en el camino. Pero también sabemos que es muy influenciable, y que sus compañeros de viaje también pueden hacer que una vez más adopte unas sendas erróneas. Lo sabremos mas pronto que tarde lo que sucederá con él, pero una cosa es clara: el camino no será fácil ${ }^{68}$. Tanto es así, que después de haber huido a Bélgica el 30 de octubre de 2017, y haberse instalado allí, al contar con ciertos apoyos no sólo entre los nacionalistas flamencos, sino también sotto voce por parte del Gobierno belga, el 25 de marzo pasado, a las 11:14 horas, fue detenido en Alemania y posteriormente encarcelado, en espera de que se resolviera si se le entregaba o no a España en cumplimiento de la euroorden lanzada por el juez del Tribunal Supremo español, Pablo Llarena. En este sentido la Fiscalía del Land alemán Schleswig-Holstein pidió el pasado 3 de abril la extradición a España, al comprobar que la euroorden del juez Pablo Llarena era «admisible» en su totalidad, y esta misma opinión se confirmaría después por la misma Fiscalía.

Sin embargo, meses después, el Tribunal de este land alemán rechazó la entrega por rebelión, aunque sí la aceptó por malversación, si bien la decisión

68 A este respecto, véase el artículo publicado en el diario ABC, de Madrid, del 3 de enero de 2018, de Salvador Sostres, con el título «Puigdemont especula con volver oculto en un barco». 
de fondo se ha adoptado definitivamente, tras varias peripecias procesales, el 12 de julio de 2018. Como se sabe, esta decisión del Tribunal alemán del Land de Schleswig-Holstein no ha sido aceptada por el juez Llarena del Tribunal Supremo español, habiendo retirado además las euroordenes lanzadas no solo contra Puigdemont, sino contra el resto de encausados que se encuentran en Bélgica y en el Reino Unido.

Sin entrar aquí en un estudio profundo sobre la denominada «Euroorden ${ }^{69}$ que entró en vigor el 1 de enero de 2004, la Orden de Detención y Entrega (ODE) es un mecanismo simplificado de detención y entrega entre los Estados miembros de la Unión Europea en plazos mucho más breves que si se recurre al procedimiento mucho más complejo de la extradición, y ello se debe a que ambos procedimientos parten de una filosofía y objetivos distintos. $\mathrm{Y}$ es que la Euroorden no se ve en la Unión como si fuera un acto de auxilio o de ayuda, cosas típicas e inherentes en la extradición, al ver en esta un conflicto de soberanía entre Estados, sino que se aborda como algo común, e incluso cotidiano, en un espacio de cooperación judicial y de solidaridad como es el europeo, partiendo en general de la obligación de entrega de la persona solicitada porque se le imputa un delito. Como señala a este respecto la Profesora Araceli Mangas, «la obligación en la UE es extraditar, denegar es la excepción, $\mathrm{y}$ hay que justificarla de forma estricta $»^{70}$.

Pero es que además, sin entrar aquí en la cuestión de saber si la decisión del Tribunal alemán ha aplicado bien o no la euroorden, lo que hay que recalcar es algo más trascendental, pues como la autora señala, si lo que ha ocurrido en España, hubiera tenido lugar en Alemania, nunca hubiera llegado a ser delito, porque no habría renunciado a la responsabilidad política de hacer aplicar la Constitución ni se hubieran sentido acomplejados por recurrir a la vía política de la «coerción federal»y prevenido e impedido el delito tomando las «medidas necesarias», todas, con tal de impedir la alta traición. Es lo que debió hacer el Gobierno de España con la primera Declaración, o en 2014 al convocar el

69 A este respecto, ver Decisión marco (DM) del Consejo de 13 de junio de 2002 (2002/584) relativa a la orden de detención europea y a los procedimientos de entrega entre Estados miembros. $D O$ L 190 de 18.7.2002 (modificada por Decisión Marco de 2009/299, DO L 81 de 27.3.2009).

70 Ver MANGAS MaRTín, A., «Euroorden versus extradición: discordancias en el (des) concierto europeo», ARI 50/2018, de 17 de abril de 2018, p. 3. La autora recoge así las expresiones que utilizó el Tribunal de Justicia de la UE en el Asunto Aranyosi y Caldararu, C-404/15, y que ella misma cita. Ibid, nota 6 . Esta autora ha publicado además múltiples artículos de prensa, sobre todo en $E l M u n d o$, en torno a la cuestión catalana, mostrándose, sumamente crítica con la actuación del Gobierno Central, sobre todo por su falta de acción, es decir su inacción. 
primer referéndum, o en 2015 al retomar la hoja de ruta, o el 6-7 de septiembre de 2017 al acordar convocar el segundo referéndum y aprobar la Ley de Transitoriedad jurídica que abolía el Estado español de Cataluña al margen de su procedimiento de revisión, la división de poderes y derogaba la Constitución en Cataluña ${ }^{71}$. Este argumento es el que está detrás de los análisis que lleva a cabo el autor de estas líneas en este trabajo, del principio hasta el final, de ahí la expresión que utilizamos del «desgobierno de los Gobiernos de España».

Este asunto de la cooperación judicial alemana también ha sido comentado recientemente por el que fuera Fiscal General del Estado con el Gobierno de Mariano Rajoy, Eduardo Torres Dulce, para quien «el Tribunal que rechazó la euroorden dictada contra Carles Puigdemont desbordó la norma europea y la vació de contenido al interpretar los hechos a la luz de la jurisprudencia alemana y no atenerse al relato del juez instructor español». Este Fiscal General se alinea así claramente con aquellos que han criticado la forma de proceder de la jurisprudencia del Land alemán encargado de ejecutar la entrega. Y es que Torres Dulce parte de la premisa de que la Decisión Marco «... deja claro que en el caso de que el Estado que ha de ejecutar la entrega opte por examinar el requisito de la doble imputación debe partir exclusivamente de los hechos que consten en la solicitud del Estado emisor de la euroorden. Debe comparar los hechos descritos con los delitos tipificados en su propio marco jurídico. No es posible por lo tanto, un examen de la tipicidad; es decir de los elementos constitutivos de ese delito o de las interpretaciones que pudieran surgir acerca de esa tipicidad. Tampoco las dudas sobre la calificación jurídica de tales hechos. Esas claras restricciones que impone la Decisión Marco se deben a que para toda la euroorden rige el principio inspirador de la confianza mutua entre Estados de la UE, verdadero motor de esta norma y no solo, como pretenden algunas interpretaciones sin base alguna, para el catálogo de delitos expresados en el artículo 2.2». Así pues, es obvio que el tribunal alemán ha entrado indebidamente en un examen del relato fáctico español justificativo de su tipicidad como delito de rebelión, haciéndolo desde la perspectiva alemana, que es justamente la que prohíbe el artículo 2.4 de la Decisión Marco. Todo esto trae consigo que la retirada de la petición de entrega por parte del Juez instructor Llarena, fuera coherente con la norma europea ${ }^{72}$.

71 Ver ibid., Conclusiones, pp. 11-12.

72 Torres Duce, E., «Schleswing-Holstein: baile de máscaras», El País, del 15 de agosto de 2018, en: https://elpais.com/autor/eduardo_torres_dulce_lifante/a (consutado el 15.08.2018). 
De toda esta historia, lo que no se explica por parte del Gobierno español es que con los delitos cometidos por el exPresidente catalán Puigdemont no se le haya detenido antes de su huida de España, y es esto lo que no se entiende bien en Europa. Es más, existe un sentimiento de que el Gobierno español ha mirado para otro lado, permitiéndole sotto voce la huida, generándose así un descrédito para España de gran consideración, pues existe el sentimiento de que siendo un asunto interno español, que hubiera debido resolverse a nivel interno con las armas de un Estado de derecho, el Gobierno ha exportado el problema fuera, obligando a los Estados, sobre todo de la Unión Europea, a tomar cartas en el asunto catalán. Si a esto añadimos la mala comunicación que ha utilizado el Gobierno para contrarrestar la campaña publicitaria de los independentistas catalanes, y su consabida pusilanimidad a la hora de hacer frente a la crisis, tenemos el cóctel perfecto de un Estado que no ha estado a la altura de las circunstancias, si se toma en consideración la gravedad de la crisis, y sobre todo a la luz de las últimas informaciones que están proporcionando las fuerzas y cuerpos de seguridad del Estado.

Pero si la cooperación judicial europea no le ha ido bien a España, muy diferente ha sido la actitud de las Instituciones de la Unión. Tanto el Presidente de la Comisión, Jean-Claude Juncker, como el Presidente del Parlamento Europeo, el italiano Antonio Tajani, se ha pronunciado en numerosas ocasiones sobre el respeto al orden constitucional español, afirmando al mismo tiempo que España era un Estado democrático, rechazando por lo tanto que hubiera presos políticos. Mucho más mitigadas han sido, sin embargo, las declaraciones del Presidente del Consejo Europeo, el polaco Donald Tusk, quien sin embargo no ha hecho afirmaciones tan categóricas, centrándose sobre todo en el diálogo ${ }^{73}$. Por otro lado, tanto Jean-Claude Juncker como Antoni Tajani se han referido en numerosas ocasiones a que la crisis catalana debía resolverse a nivel interno español, rechazando las solicitudes de mediación hechas por los líderes independentistas catalanes ${ }^{74}$. Algo similar ha ocurrido

73 Hay que recordar que la Unión Europea recibió el Premio Principe de Asturias de la Concordia 2017, y en los discursos de agradecimiento Jean-Claude Juncker terminó con un «Viva España». Ver «Jean-Claude Juncker: «La fuerza de Europa en la regla del Derecho», en: https:// www.abc.es/cultura/abci-premios-princesa-asturias-juncker-fuerzaeuropa-fundamentarse-regla-derecho-201710202012_noticia.html [consultado: 14/08/2018].

74 Conviene apuntar que en realidad esto les es impuesto por el propio Tratado de la UE, cuyo artículo 4.2 señala que «la Unión respetará la igualdad de los Estados miembros ante los Tratados, así como su identidad nacional inherente a las estructuras fundamentales políticas y constitucionales de estos, también en lo referente a la autonomía local y regional. Respetará las funciones 
con los Estados salvo algunas excepciones, como Bélgica, Eslovenia, Estonia o Finlandia, cuyos posicionamientos un poco ambiguos fueron neutralizados rápidamente por países como Francia, Alemania o el Reino Unido. A nuestro entender, la clara y contundente posición francesa, defendiendo la integridad territorial española frente a las tesis independentistas ha sido crucial, como se ha puesto de manifiesto con las declaraciones y posicionamientos públicos del exMinistro Manuel Valls en numerosas ocasiones, pero también del Gobierno en general, sin olvidar al propio Presidente de la República.

\section{LAS ELECCIONES DEL 21 DE DICIEMBRE CONVOCADAS POR EL GOBIERNO CENTRal para Elegir al Parlamento de la Comunidad Autónoma: Algunas REFLEXIONES}

Como se sabe, y como parte de la intervención por parte del Gobierno español de la Comunidad Autónoma catalana a la luz del artículo 155 de la Constitución, el Jefe del Gobierno español, Mariano Rajoy, decide convocar elecciones en la región para el 21 de diciembre del 2017. Debe hacerse hincapié en que esto no es un referéndum sobre la independencia, sino sólo elecciones para elegir a los miembros del Parlamento catalán. Las elecciones se llevarían a cabo con todas las garantías necesarias en un Estado democrático, como todo el mundo ha podido comprobar, y sin incidentes. Los separatistas no pueden, por tanto, quejarse ni de urnas robadas ni de presiones ni de cualquier fraude electoral, tal como se anunció justo antes de las elecciones. Las elecciones fueron, pues, limpias, muy lejos, por tanto, del referéndum del $9 \mathrm{de}$ noviembre de 2014, y del celebrado el primero de octubre, ambos ilegales y sin garantías democráticas.

Los resultados pueden ser objeto de diversas interpretaciones, pero lo que está claro es que los anti-separatistas obtuvieron el 50,9 por cien de los votos, y la mayoría de diputados la obtuvo los independentistas en virtud de la aplicación de la ley d'Hondt. La idea de que los catalanes quieren abrumadoramente la independencia, como algunos medios publicaron, siguiendo así el discurso independentista, no solo resultó ser falsa en este caso, sino que siem-

esenciales del Estado, especialmente las tienen por objeto garantizar su integridad territorial, mantener el orden público y salvaguardar la seguridad nacional. En particular, la seguridad nacional seguirá siendo responsabilidad exclusiva de cada Estado miembro». 
pre fue falsa. Dicho esto, es preciso que los separatistas comprendan que la vía unilateral es ilegal, ha fracasado, y que, además, la comunidad internacional no la quiere ${ }^{75}$. La solución tiene pues que venir al marco jurídico interno español, y es aquí donde tenemos que llegar a un acuerdo respetando nuestro marco constitucional, el del presente o el del futuro. Es evidente que España no se romperá por los caprichos de unos pocos visionarios que sueñan con un paraíso no para su pueblo, sino para ellos mismos.

En este sentido, cabe señalar que el movimiento de independencia está muy aislado a nivel internacional y nacional, existiendo también una gran rivalidad entre los distintos grupos políticos, especialmente entre el partido de Puigdemont y el de Junqueras, en la actualidad en prisión. Por otro lado, no hay que olvidar que la justicia española continúa su camino, poco a poco, pero de manera implacable, algo que no esperaban, por lo menos al nivel que lo están haciendo. Creían que, al invocar su concepto de la democracia, tendrían alguna impunidad para violar la ley. Pero una vez más, se han equivocado, ya que los tribunales españoles mantienen actualmente 37 casos abiertos contra los líderes separatistas y en torno a una veintena de casos contra los jefes de la policía regional por desobediencia a la autoridad judicial e inactividad durante el referéndum ilegal del primero de octubre, etc., etc. ${ }^{76}$. El 4 de enero de 2018, el señor Junqueras tenía una cita de nuevo en el Tribunal Supremo español para examinar el recurso presentado contra su encarcelamiento, en la que exigió su liberación.

Los tres jueces de la Cámara de Apelación decidieron justo un día después, en una sentencia muy dura y por unanimidad, rechazar la apelación, permaneciendo así en la cárcel y allí siguen. Los argumentos de Junqueras no convencieron a los jueces, aunque insistió, en un hecho extraordinario, su creencia en la fe católica, y también que era un hombre de paz. Los jueces dicen que los delitos que se le imputan, y que están probados, demuestran todo lo contrario, teniendo en cuenta que contribuyó a los actos de violencia cometidos el 20 y el 21 de septiembre frente a la sede del Departamento de Economía de la Generalitat que él dirigía. Además, los jueces señalan que nunca renunció a la vía unilateral de independencia, algo que sí que han hecho otros separatistas, como la Presidenta del Parlamento catalán, Carme Forcadell ya liberada. Por lo tanto, si el Gobierno de Rajoy no ha estado a la altura

75 Ver FernándeZ Liesa, C., «El 'próces' no tiene apoyos», El País, 30 de noviembre, 2017.

76 Para más detalles, véase Reguero, María «La justicia ha abierto 37 causas contra el próces» $E l$ Mundo, 2 de enero, 2018. 
de las circunstancias, a pesar de la gravedad de la situación, la máquina judicial ha funcionado muy bien y ha sido capaz de afrontar el reto como corresponde a un Estado de Derecho.

Esto no es una especie de justicia divina, pero en el caso que nos ocupa, podemos decir que casi... ${ }^{77}$. Todo esto ha traído consigo que los diputados independentistas catalanes tuvieran muchas dificultades a la hora de formar gobierno en Cataluña, aunque al final lo consiguieron. Lo que no pudieron conseguir fue nombrar a Puigdemont como Presidente, a pesar de que estaba fugado de la justicia española en Bélgica.

\section{La MOCión de CENSURa AL PREsidente del GobieRno, MaRiano RAJOY, Y LA OFERTA DE DiÁLOGO}

En estas circunstancias tan complejas y controvertidas iba a suceder un hecho relevante, en el que iban a participar de forma muy activa los partidos independentistas catalanes: se trata ni más ni menos de la moción de censura presentada y aprobada, el 1 de junio pasado contra el Presidente del Gobierno, Mariano Rajoy.

Conviene recalcar, a este respecto que se han presentado en todo el período democrático español cuatro mociones de censura: contra el Presidente Adolfo Suárez en 1980, contra Felipe González en 1987 y dos contra el Presidente Rajoy, una en 2017 y la del 1 de junio pasado, que es la única que ha sido aceptada por 180 votos a favor, 169 en contra y una abstención, siendo, pues investido el candidato socialista Pedro Sánchez como Presidente del Gobierno. No es en este trabajo en donde se va a examinar todas las causas que han llevado a esta situación, pero es evidente que detrás de la moción está, como una causa más, pero relevante la crisis catalana. Todavía es pronto para ver si este repentino cambio de Gobierno, y sin elecciones, va a tener repercusiones importantes a la hora de abordar el tema catalán, sin que el diálogo tendido por ahora al

77 Sobre esta segunda cita de Junqueras con la Justicia, véase Rincón Reyes «El Supremo deja en la cárcel a Junqueras porque no renuncia a la vía unilateral», en: https://politica.elpais.com/politica/2018/01/04/actualidad/1515096723_185651.html [consultado: 14/08/2018]. Asimismo, HERRERA, C., «Ese hombre de paz. La vida está llena de hombres de paz que no tienen inconveniente en subvertir la legalidad», en: http://www.abc.es/opinion/abci-hombre-201801051357_noticia. html\#ns_campaign=rrss-inducido\&ns_mchannel=abc-es\&ns_source=mail6ns_link... [consultado: $14 / 08 / 2018]$. 
Gobierno catalán y a los partidos independentistas por parte del Gobierno de la Nación hayan producido los resultados esperados. Y es que mientras el Gobierno Central reafirma una y mil veces que no hay derecho de autodeterminación, el Gobierno catalán hace de este derecho el pilar fundamental para que más pronto o más tarde se haga efectiva la «República catalana». Las amenazas de crear la República catalana son tales que parten del referéndum del 1 de octubre como si fuera un referéndum válido, a pesar de ser anticonstitucional.

Es evidente que este discurso que se sitúa obviamente fuera del marco constitucional español, es plenamente incompatible con el espíritu de diálogo y de negociación que le ofrece el nuevo Gobierno Central, que no deja de ser el Gobierno de todos los españoles, entre los que están incluidos obviamente los catalanes. Y es que, como ya se ha apuntado «... algunas de las propuestas expresadas en torno a la cuestión catalana buscan transformar la relación vertical de las partes en el marco constitucional en una relación horizontal o paritaria, de poder a poder, al margen de la ley o, mejor contra la ley. Implican el reconocimiento del becho revolucionario y la inevitable consumación de sus efectos. No tienen por objeto reconducir sus pretensiones dentro del Estado de Derecho que ha venido violentando sino, por el contrario, consolidar la secesión negociando con el Gobierno central una sucesión pactada. Reclamar una mediación internacional es el colofón de esta pirueta» ${ }^{78}$.

Dicho esto, lo que no se entiende es el hecho de que los independentistas catalanes, catapultados por sus líderes en una fosa, hagan continuas referencias al concepto de democracia como si el Estado español no lo fuera. Este discurso tan reiterativo, y al mismo tiempo tan repelente, ignora un principio tan esencial en un Estado soberano que es el hecho de que corresponde al pueblo español en su conjunto el que tiene esa titularidad, incluidos por supuestos los catalanes. España, como Estado democrático que es, guste o no a los independentistas catalanes, es un Estado de Derecho, y es el conjunto de la ciudadanía española la que tiene el derecho a decidir su destino y a elegir el sistema económico, político y social que estime pertinente. Lo antidemocrático sería que una minoría de esa población, en este caso la catalana, pudiera imponer al resto de españoles su voluntad, pues no es este el marco constitucional del que España se ha dotado. Esto no quiere decir que no se pueda reformar la Constitución, si el pueblo español así lo decidiera, pero esto es harina de otro costal.

78 Remiro Brotons, A.; ANdrés Sáenz de Santamaría, P., «La cuestión catalana», op. cit., p. 287. 


\section{CONCLUSIÓN}

La crisis catalana ha puesto a España, uno de los países más antiguos del continente europeo, en el tapiz de la actualidad internacional. La crisis de identidad a la que se ha visto sometida recientemente se debe simplemente al hecho de que una minoría de su pueblo tuvo la ocurrencia de invocar el derecho a la autodeterminación, un derecho que ha sido creado y diseñado exclusivamente para los pueblos coloniales. Aún más, esa minoría, que goza de plenos derechos culturales, lingüísticos y políticos, garantizados por el Estado español, como un verdadero Estado democrático que es, no ha dejado de sembrar el odio contra el pueblo y el Estado español, Estado que nos representa a todos.

Sin embargo, es necesario resaltar que el Gobierno Central, cuya tarea es la de mantener el orden y la seguridad nacional, mostró una gran dosis de debilidad y negligencia, incluso podría decirse que muy graves a la hora de hacer frente a un reto tan importante para toda la sociedad española a nivel nacional, poniendo así en peligro los vínculos y la vida común que durante siglos los diferentes pueblos de la nación española han mantenido vivos, a pesar de nuestras aventuras y conflictos nacionales. No obstante, las señales que daban los iluminados líderes independentistas eran tan claros que solo un ciego no podía verlos. Pero el Gobierno Central no ha escuchado tampoco las advertencias que llegaban a la Moncloa con respecto a una situación como la que se estaba desarrollando. La responsabilidad del jefe del Gobierno español es pues grandiosa, ya que tuvo que intervenir el Jefe de Estado, el rey Felipe VI, para mostrar a los españoles que se respetaría el orden constitucional español, y que los iluminados independentistas habían violado la lealtad constitucional. Fue en este ambiente cuando el pueblo español, como en otras ocasiones, ocupó las calles de Barcelona...

La responsabilidad del partido que gobernaba España en esta crisis ha sido tan clara que los votantes catalanes han castigado severamente al Partido Popular de Mariano Rajoy, al haber obtenido una representación casi simbólica en las elecciones del 21 de diciembre. Por último, sólo la justicia, las fuerzas de seguridad, a excepción obviamente de la policía catalana, y el pueblo español han estado donde debían estar, salvando así al país de un desgarro cuyos efectos hubieran sido desastrosos para España y, quizás también para Europa. Ahora queda por saber si se ha aprendido la lección o no, pues como se suele decir el hombre es el único animal que tropieza dos veces con la misma piedra. Otra cosa que no se puede entender es el hecho de haber mantenido la 
estructura de los «Mossos d'Esquadra», la policía catalana, pero que paga en gran medida el Ministerio del Interior, cuando se sabe que al menos alrededor del $55 \%$ de sus miembros eran independentistas, y sus principales líderes también. En nuestra opinión, es evidente que esta policía debería haber sido desmantelada, pues una policía de esta magnitud, después de haber tenido la despreciable conducta que ha tenido el 1 de octubre, no tiene la confianza de la sociedad española.

No hay que olvidar que Puigdemont, que huyó a Bélgica, su país de asilo, acompañado por un miembro de esta policía, y unas pocas docenas de sus miembros, especialmente los líderes, ya están imputados de varios delitos muy graves por los tribunales españoles, tales como sedición, obstrucción a las otras policías, desobediencia a órdenes judiciales, etc., etc. Las informaciones que están saliendo ahora respecto a la connivencia de los jefes de esta policía con el mundo independentista son abrumadoras, pero ahí siguen. ¿Podemos por lo tanto confiar en una policía, cuyos miembros se han comprometido y jurado respetar la Constitución, una vez que vimos no sólo su comportamiento pasivo, sino la colaboración activa con los líderes separatistas? Parece que el Gobierno Central ya ha olvidado lo sucedido en Eslovenia en junio y julio de 1991 durante la Guerra de los Diez Días o ¿no quiere saberlo?

Por su comportamiento, parece que la ignorancia reinaba en el Gobierno español, aunque este país no está lejos..., y esto a pesar de la clara simpatía que mostró el Gobierno esloveno, por lo menos «en voz baja», por el independentismo catalán. Pero que la directora de la Escuela de los Mossos de d'Esquadra esté acusada de haber transportado urnas para el referéndum del primero de octubre, y que haya sido descubierto recientemente, revela algo muy grave, que es la falta de presencia del Estado español en una región que desde hace décadas ha estado construyendo sus estructuras estatales mientras que los Gobiernos españoles estaban en el limbo.

El nuevo Gobierno que se ha instalado en Madrid tras la moción de censura, dirigido por el Presidente Pedro Sánchez, moción de censura que salió adelante con el apoyo de los partidos independentistas catalanes y vascos, incluido el Partido Nacionalista Vasco, ha cambiado el paso del Gobierno Central, al abrir con el Gobierno de la Comunidad Autónoma catalana un diálogo cuyo resultado en estos momentos dista mucho de ser positivo al medio y largo plazo, ya que el Presidente del Gobierno catalán, el supremacista Quin Torra, no deja de lado las tesis radicales independentistas como son el derecho de autodeterminación y las referencias continuas al 1 de octubre y a la necesidad de un referéndum para votar en Cataluña la denominada República, es 
decir la independencia. Con este espectro de reivindicaciones será muy difícil establecer un marco de negociación en el que se respete la Constitución española, o lo que es lo mismo, los derechos de todos los españoles, pues tanto los catalanes, como el resto de ciudadanos, somos españoles.

Es evidente que el tema catalán ha trascendido ya nuestras fronteras, lo que nunca hubiera debido ocurrir, puesto que debe ser resuelto pura y simplemente a nivel interno español. La dejadez de nuestros gobiernos, y la mala praxis política lo han permitido, a pesar de las advertencias que se han lanzado por algunos conocedores de estos temas, aunque es cierto que no por todos, y por parte de la mayoría de Estados europeos, así como de las Instituciones de la Unión Europea. Desde esta perspectiva, la irresponsabilidad de los distintos gobiernos españoles, sobre todo los últimos, y de forma clarísima el que ahora nos gobierna, está fuera de toda duda, lo que ha permitido que fuera de nuestras fronteras se dude de lo que realmente quiere España. Una prueba de ello es la opinión expresada últimamente por un autor francés, quien no duda en señalar lo siguiente:

«Si les autorités centrales espagnoles en venaient à accepter la séparationhipothèse certes pour l'heure peu vraisemblable, mais non à exclure à priorice revirement transformerait la sécession en dévolution, attirant de ce fait de nombresuses reconnaissances (car plus rien si ce n'est peut-être la crainte de l'effet mimétique du phénomène sécessionniste ne justifierait de refuser à la Catalogne l'indépendance que lui accorderait l'Etat-mère), jusqu'à la masse critique nécessaire à une objectivation consistante constitutive du statut international d'Etat de la Catalogne» ${ }^{79}$.

La pelota sigue estando donde siempre ha estado, es decir en el tejado español, sin que nuestros gobiernos, y sus acólitos más directos, hayan estado a la altura de las circunstancias, al situarse en un limbo de irresponsabilidad magistral...

79 WhiLer, E., «La déclaration d'indépendance de la Catalogne: sécession, non-ingérence et (non-)reconnaissance», Revue générale de droit international public, 2018, p. 865. 